\title{
Study on the long-hole raising technique using one blast based on vertical crater retreat (VCR) multiple deck shots
}

\author{
Kewei Liu ${ }^{1}$, Jiacai Yang ${ }^{1}$, Xibing $\mathrm{Li}^{1}$, Hong $\mathrm{Hao}^{2}$, Qiyue $\mathrm{Li}^{1}$, Zhixiang $\mathrm{Liu}^{1}$ and Chunyi Wang ${ }^{3}$ \\ ${ }^{1}$ School of Resources and Safety Engineering, Central South University, Changsha, China \\ ${ }^{2}$ School of Civil Engineering, Guangzhou University, Guangzhou, China and Centre for Infrastructure \\ Monitoring and Protection, School of Civil and Mechanical Engineering, Curtin University, Western \\ Australia, Australia \\ ${ }^{3}$ Sandaozhuang Mining Company, China Molybdenum Co., Ltd., Luoyang, China
}

\begin{abstract}
Backfilling inaccessible cavity through raise can provide underground support for the active open-pit operations and the raise must be taken down in a single blast for safety reasons. Conventional raising techniques are not economically and technically feasible, and the maximum advance depth in one blast is limited. In this paper, small-scale crater tests were carried out in a site with cavities and field blasting test data were measured and evaluated to obtain the basic data for raise-scale blast designs. The raising design parameters with $250-\mathrm{mm}$ hole diameter, including charge weight and height for each slice, slice height, hole spacing and delay interval, were derived. A scheme of multiple deck blasting based on vertical crater retreat (VCR) drop-raising method was designed for an abandoned cavity with $30-\mathrm{m}$ cover. The lower $12-\mathrm{m}$ cover was first blasted to investigate the practical blast performance. Charging and timing patterns were adjusted accordingly and the left $18-\mathrm{m}$ cover was successfully opened up. Through raising tests, it is shown that the advantage of two available free surfaces up and down should be maximized, and smaller slice height and alternate initiation sequence are benefit for raising extension. A numerical model is then developed and it is calibrated against the 12-m raising test. By combining the calibrated numerical model with the raising test results, the effects of hole layout and in-slice delay are examined. It is shown that circular pattern and in-slice delay are positive for multiple-deck raising blast. Based on the foregoing analysis, the hole layout, charging and timing patterns are optimized. The optimized scheme was applied to field raising blast and a 32-m raise was successfully excavated in one blast. It demonstrates that by using this long-hole raising technique of VCR multiple deck shots, the raising length in one blast can be greatly increased.
\end{abstract}

Keywords: Abandoned cavity, long-hole, raising blast, VCR drop-raising, multiple deck shots, numerical simulation.

\section{Introduction}

The existence of inaccessible abandoned cavities, which have been created by previous underground mining activities, imposes a potential hazard to current active aboveground mining operations. When the overlying strata becomes relatively thin during open-pit mining, the roof of cavity is highly susceptible to collapse due to bench blasting or repeated loading from the 
aboveground production vehicles, which endangers the safety of workers and heavy equipment and retards the open-pit mining progress [1-2]. It is therefore necessary to backfill the abandoned cavities, when their covers are thick enough, to provide underground support.

In practice, large-diameter borehole/pipeline and raise are commonly used to deliver the backfill materials into the underground mined-out area [3-4]. For the large-diameter borehole/pipeline, classified mill tailings and alluvial sands are suitable to allow trouble-free transport, but these backfill materials are needed to be prepared and characterized by low-strength and low-efficiency during backfilling. On the other hand when rock fill is used, the borehole/pipeline can be easily blocked. Moreover, for a large cavity, the backfill materials pumped into the cavity can only occupy a small room near the borehole/pipeline. Raises are essentially small upside down shafts and developed for a variety of purposes, such as ore and waste passes, ventilation passes, and slot raises in production stopes. Compared to the boreholes, backfill raise is compatible even with rock-fill materials due to its bigger cross section, which also contributes to higher efficiency of backfilling. In open-pit mines, rock fill generally refers to waste rock and its main attraction has always been the availability at mine sites. It is therefore a preferred option to backfill the underground cavities from ground surface through raises with rock fill. However, excavating raise is considered the most dangerous in all the development headings. Many serious accidents and fatalities caused by falls of ground have occurred in raise work over the years because access to raise face is often more difficult and unsafe. Fortunately, raising safety has been drastically improved by the development of new equipment and innovative blasting methods.

The significant developments of equipment that have improved raise access and working safety are the Alimak raise climber and raise-boring machine [5-6]. Alimak raise climber makes use of a rail mounted work platform to transport workers to the raise face with normal drill and blast methods, and its platform has a shield that protects miners from rock falls. However, this method is quite labour intensive and costly, and the only access for this equipment to develop raises is from the bottom. Abandoned cavities are usually unsafe to enter due to the extremely poor underground conditions, and therefore make such equipment not applicable. Although raise-boring is a safe and successful method, it is also very expensive [7].

On the other hand, several blasting technique innovations have also improved the raising safety. In Canada in 1975, mining company INCO developed a mining method based on Livingston's cratering theory. This method is called vertical crater retreat (VCR) or vertical retreat mining (VRM) method. VCR method has been an established mining method being practiced in various mines all over the world [8]. An offshoot of this mining method is the VCR drop-raising technique that employs the same spherical crater charge technology as VCR method [9-10]. This technique has vastly improved raise blasting safety because top loading no longer requires workers to be underneath the freshly blasted and dangerous ground. VCR drop-raising method is also very cost effective because relatively less number of large holes is required, and this method is also very forgiving to moderate 
levels of hole-deviation. Miners have been refining this technique for almost 30 years and holes size for this application generally varies from 102 to $165 \mathrm{~mm}$. It is widely used to develop backfill raises. However, VCR drop-raising is labour intensive. In this method, vertical large-diameter holes are drilled on a designed pattern from the ground surface or an overcut into the roof of the cavity, and spherical charges of explosives are placed in these holes at a calculated optimum distance from the bottom of the holes and detonated, a vertical thickness of rock mass will be blasted downwards into the cavity. After the first blast, the procedures of charging and blasting need to be repeated for the next same thickness of rock mass, and raising in the rock mass retreats in the form of horizontal slices in a vertical upward direction until the top slice is blasted and the raising is completed. VCR drop-raising essentially consists of a series of independent small shots. The existence of underground cavities makes it potentially dangerous to approach the ground after the first blast, which leads to that the raising must be taken down in a single blast, and therefore makes the conventional VCR drop-raising technique not applicable to excavate backfill raises over abandoned cavities.

In order to achieve greater raising advance in one blast, some innovative blasting techniques have been tried but few reports can be tracked. Multiple deck shots in the VCR drop-raising was attempted by Sterk [11] at the Homestake mine but with poor performance. Using electronic detonators and creating stemming separation between decked charges, several Canadian mines have successfully carried out a series of up to three sequentially delay decked charges (normally $3 \mathrm{~m}$ per slice) to extend the length of advance [10]. Besides the VCR drop-raising-based techniques, long-hole drop-raising technique can also be used to blast raises. This technique uses smaller holes, ranging from 51 to $89 \mathrm{~mm}$, and burn cut to provide relief. It can be charged from either the bottom up or the top down. Sterk [11] also practiced long-hole drop-raising at the Homestake mine, and single deck shot usually advanced the raise $3.048 \mathrm{~m}$. Multiple deck shots were also tried but with low success rate. Fellows and Stolp [12] reported that using 76-mm diameter holes and a standard long-hole drop-raising pattern of 2.4-m spacing by $2.4-\mathrm{m}$ burden, a raise with length up to $15.25 \mathrm{~m}$ was advanced in a single blast. In addition, it was reported that using an inverse drop-raising technique, a raise was blasted with a single blast up to $15 \mathrm{~m}$ from the bottom up at Elandsrand mine [13]. The greatest advance in one blast has been reported is the 29-m inverse drop-raising at Health Steele Mines [14], which was designed and blasted by the blasting technology personnel from the Noranda Technology Centre in the fall of 1997. In this case, the raise and two blast rings were taken down by one blast with twenty-five long up-holes of $114 \mathrm{~mm}$ in diameter. Inverse drop-raising technique is essentially similar to the long-hole drop-raising technique, and the main difference is that it must be drilled and charged from the bottom up. Same as the burn cut of long-hole drop-raising method, it is also necessary to provide the initial relief volume, thus a $0.76-\mathrm{m}$-diameter raise bore in this case had to be drilled first. Therefore, the inverse drop-raising technique is not technically and economically feasible for abandoned cavities, and developing the long-hole raising technique using one blast for 
inaccessible abandoned cavities which have covers with large vertical thickness is still a big challenge.

This paper studies the effectiveness of long-hole raising technique using one blast to excavate backfill raises for inaccessible abandoned cavities in an open-pit mining site. A series of small-scale crater tests based on Livingston's cratering theory were carried out in the site and field blasting test data were measured. Data analysis and evaluation were performed to obtain the basic data for the raise-scale blast designs. With 250-mm hole diameter, the raising design parameters, including charge weight and height for each slice, slice height, hole spacing and delay interval, were derived. Aiming at an abandoned cavity with 30-m cover, a scheme of multiple deck blasting based on VCR drop-raising method was designed. To investigate the blast performance in practice, this raising blast was altered and divided into two single blasts. The first blast based upon VCR drop-raising method was to raise the lower 12 meters of the cover, after that, the shape and dimensions of the freshly blasted raise was obtained by laser scans and the blasting result was analysed. Then the raising of upper 18 meters was redesigned and blasted. Through these two single blasts, the 30-m cover was successfully opened up. According to the first raising blast, a detailed 3D finite element model is constructed in ANASYS, and LS-DYNA is employed to simulate the raising process. The numerical model is calibrated against the raising test data. By combining the calibrated numerical model with the raising test results, the effects of hole layout and in-slice delay are examined, and the hole layout, charging and timing patterns are optimized. The optimized scheme is applied to a 32-m raising blast and the cover is successfully broken through in one blast.

\section{Site background}

The Sandaozhuang molybdenum mine is located $3.6 \mathrm{~km}$ to the east of the town of Lengshui in Henan province of China. Industrial-scale extraction at this mine site began in the late 1960s and underground operations were the principal mining methods. Owing to the lack of planning and authorization, uncoordinated underground mining and spoliation of molybdenum-rich ores ever happened from the middle 1980s to early 1990s. In 2002, the underground production was totally converted to open-pit operations. After more than 30 years of underground mining, large amounts of underground cavities with a total volume of around $2 \times 10^{7} \mathrm{~m}^{3}$, according to the latest statistics, were left. Currently, the left cavities are mainly located at elevations from 1160 to $1366 \mathrm{~m}$.

In recent years, continuous open-pit stripping progresses toward the abandoned underground cavities. Some cavities collapsed due to adjacent bench blasting or repeated loading exerted by the aboveground production vehicles when the overlying strata became relatively thin. This situation constitutes a potential hazard to miners and heavy equipment. In order to avoid exposing aboveground mining operations to unsupported ground, the cavities under the benches are constantly surveyed using the Cavity-Autoscanning Laser System (C-ALS). The C-ALS consists of a laser unit in a motorised head that is capable of being inserted into the cavity via predrilled boreholes to locate and 
measure the cavity. However, this is obviously still not the final solution. Having considered several possible approaches, the most practical solution is to backfill the cavities with waste rock through raises, when the overlying strata are thick enough, to provide underground support.

\section{Cratering theory and tests}

\subsection{Cratering theory}

The concept of cratering and its development may be attributed to C.W. Livingston [15]. It is a versatile tool for studying the blasting phenomenon, and its application has resulted in the development of a new underground mining method, the VCR method of primary stoping, pillar recovery, and drop-raising. A crater blast is a blast where a spherical or near spherical charge $(1: 6 \leq$ diameter-to-length of charge ratio $\leq 1$ ) is detonated beneath a surface that extends laterally in all directions beyond the point where the surrounding material would be affected by the blast.

Fig. 1 shows the nomenclature used in VCR method, and they are described as follows: $\Phi$ is the hole diameter, $\mathrm{L}$ is the charge length, $\mathrm{d}_{\mathrm{b}}$ is the depth from the surface to the centre of gravity of the charge, i.e., depth of burial. When $\mathrm{d}_{\mathrm{b}}$ is such that the maximum volume of rock is broken, this burial is called the optimum depth of burial $d_{0} . r$ is the radius of crater, i.e., $0.5 \mathrm{D}, r_{o}$ is the radius of crater formed at optimum depth of burial, and $\mathrm{V}$ is the crater volume.

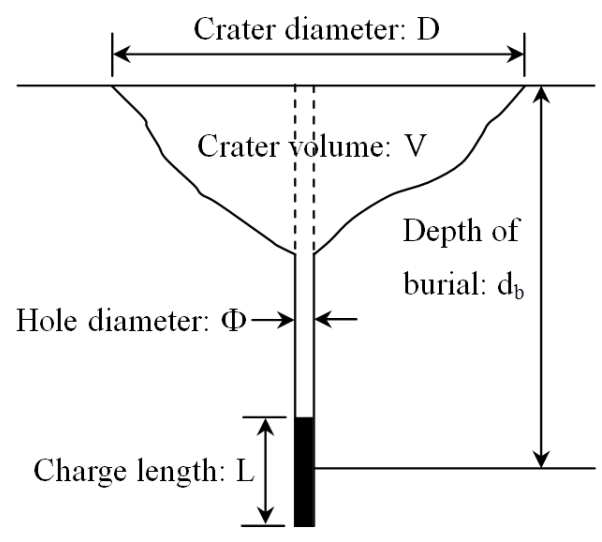

Fig. 1 Cratering dimensions

There is a definite relationship between the energy of the explosive and the volume of the material that is affected by the blast. This relationship is significantly affected by the placement of the charge. Livingston determined that a strain-energy relationship exists, as expressed by an empirical equation:

$$
\mathrm{N}=\mathrm{EQ}^{1 / 3}
$$

where $\mathrm{N}$ is the critical depth, i.e., the depth of burial at which the effects of a cratering charge are just noticeable on the surface, $\mathrm{E}$ is the strain energy factor and it is a constant for a given explosive-rock combination, $\mathrm{Q}$ is the weight of the explosive charge.

The same equation may be written in the form of:

$$
\mathrm{d}_{\mathrm{b}}=\Delta \mathrm{EQ}^{1 / 3}
$$


where $\Delta$ is equal to $d_{b} / N$ which is a dimensionless number expressing the ratio of any depth of burial compared to the critical depth. A full description of the cratering theory is given in [8].

\subsection{Small-scale crater tests}

The purpose of performing small-scale crater tests is to obtain the data required to make reliable prediction of the blasting effectiveness in VCR-raising. Since different rock properties and structural geology may lead to inaccurate prediction of the depth of burial for the VCR blasts, the crater tests should be conducted as close as possible to the rock mass where the VCR raising will be carried out. Due to development work in Sandaozhuang open-pit, it is possible to conduct the tests on the ground at the current active bench level of $1366 \mathrm{~m}$. Early and ongoing C-ALS surveys confirm that, adjacent to this crater test area, there are several large cavities located under the bench levels of $1366 \mathrm{~m}$ and $1354 \mathrm{~m}$. A field geological investigation procedure was carried out to analyse whether the rock properties and geological structure of the test area are similar to what is expected in the cover of the abandoned cavities. The geological data from the test area are compared with data between 1366-m and 1306-m levels around the cavities. The rock types of the test area and the cover are mainly Sandaozhuang skarn and hornstone. Cores from profiles indicate good-to-excellent rock. The RQD values are in the range of $75 \%-100 \%$. Through comparison to the available data of structure densities, structure lengths and RQD values, it is concluded that no major variations of rock properties and geological structure exist within the rock mass except the rock mass near ground surface is fractured to a greater extent due to active open-pit operations.

Before drilling the test holes, bentonite and gravel on the ground surface were cleared. The test holes were vertically drilled perpendicular to the ground surface. The distances between the holes are more than 5 meters. A total of twenty holes were drilled with the same hole diameter of $140 \mathrm{~mm}$. Nineteen holes were selected based on hole quality and blasted with emulsion explosives. The depth of holes ranges from 0.91 to $2.48 \mathrm{~m}$. The explosives used in the small-scale crater tests are $\Phi 90 \mathrm{~mm}$ cartridged emulsions, manufactured by Henan Qianjin Chemical Co., Ltd. For each test hole, one emulsion cartridge was stabbed in the middle with a knife, and an electric detonator, developed by Orica, was inserted. The cartridge with the detonator was lowered into the hole and tamped with a loading stick. The charging density is $1,100 \mathrm{~kg} / \mathrm{m}^{3}$, the charge weight, i.e., one emulsion cartridge is $3.0 \mathrm{~kg}$ and the charge length is about $0.17 \mathrm{~m}$. To be able to load the explosives at a specific position, extra depths at the bottom of some holes were filled with drill cuttings or sand and tamped. Stemming consists of drill cuttings and/or sand.

After firing each shot, the bentonite and gravel were cleared manually. Scaling of the crater walls was kept to a minimum and all structural weakness planes which may have influenced the size or shape of the crater were noted. Fig. $2 \mathrm{a}$ and $2 \mathrm{~b}$ show the photographs before and after the test shot No. 7. As can be seen, the shape of crater is irregular and unsatisfactory fragmentation occurred. Similar phenomena also happened in other crater tests. This is due to minor geological discontinuities present in the rock mass. The structural geology generally has a more significant influence on the cratering 
results when using relatively small charges as compared to the case with larger charges. Crater depth as a function of position was determined by using a sliding ruler. From measurements made on a $20-\mathrm{cm}$ grid, the maximum depth and radius were determined and the volume was calculated. A total of thirteen craters were formed at different depths of burial while keeping the charge weight at $3 \mathrm{~kg}$ unchanged. The data for crater tests are given in Table 1. Fig. $2 \mathrm{c}$ and $2 \mathrm{~d}$ show the photographs before and after the test shot No. 12. It can be seen that almost no crater was formed when the depth of burial is about $1.91 \mathrm{~m}$, and the rock surrounding the test hole is just cracked. In the tests, five holes with depths of burial greater than $1.91 \mathrm{~m}$ all show that no crater was formed while those with burial depth less than $1.91 \mathrm{~m}$ generated craters of different sizes as given in Table 1 . Therefore the critical depth $\mathrm{N}$ is determined to be $1.91 \mathrm{~m}$, and according to Eq. (1) the calculated strain energy factor E is about 1.32 $\mathrm{m} / \mathrm{kg}^{1 / 3}$.
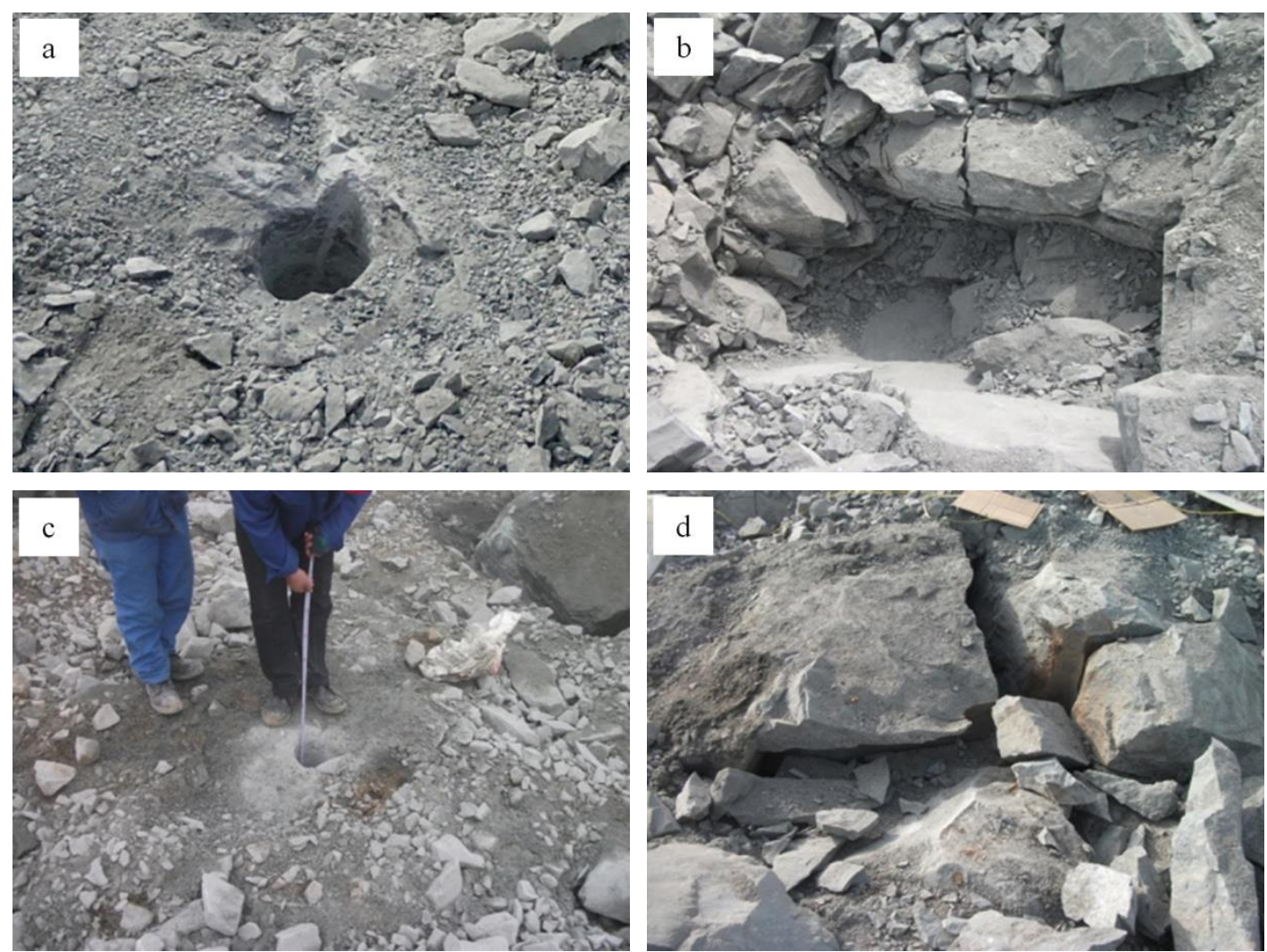

Fig. 2 Photographs before and after the test shots No. 7 and 12

Based on the data obtained, crater curve of V/Q versus $\Delta$, i.e., $\mathrm{d}_{\mathrm{b}} / \mathrm{N}$ is plotted in Fig. 3. As can be seen, the optimum depth ratio $\Delta_{\mathrm{o}}$ appears to be 0.56 . For $\Delta_{\mathrm{o}}$ equal to 0.56 and the critical depth $1.91 \mathrm{~m}$, the calculated optimum depth of burial $\mathrm{d}_{\mathrm{o}}$ for a $3-\mathrm{kg}$ charge is $1.07 \mathrm{~m}$. It can also be found from Fig. 3 that the value of V/Q corresponding to the optimum depth ratio is $0.7 \mathrm{~m}^{3} / \mathrm{kg}$ and hence the optimum volume $\mathrm{V}_{\mathrm{o}}=0.7 \times 3=2.1 \mathrm{~m}^{3}$. At this point, the following basic data have been obtained: $\mathrm{Q}=3.0 \mathrm{~kg}, \mathrm{~N}$ $=1.91 \mathrm{~m}, \mathrm{E}=1.32 \mathrm{~m} / \mathrm{kg}^{1 / 3}, \Delta_{\mathrm{o}}=0.56$ and $\mathrm{d}_{\mathrm{o}}=1.07 \mathrm{~m}$.

It should be noted here that the smooth curve in Fig. 3 has been selected to fit the experimental points. Because of the highly scattering data, the curve could have different forms, e.g., if the curve 
had been fitted using the least-squares method to a selected nonlinear equation. Therefore different or larger $\Delta_{\mathrm{o}}$ value could be obtained depending on how the testing data is processed. The interpretation of the results appears to require a considerable amount of subjective assessment on the part of the persons conducting the small-scale crater tests. This means that crater tests should preferably be carried out only by persons with previous experience in production blasting and, if possible, similar testing. For this purpose, a specially trained and experienced crew at the mine was engaged as a consultant to conduct the test shots and evaluate these parameters for the later VCR raising designs. From their viewpoint, even the current $\Delta_{o}$ of 0.56 is slightly greater because the rock near ground surface is fractured to a greater extent than those underground. This point is carefully considered when designing the raise blasting.

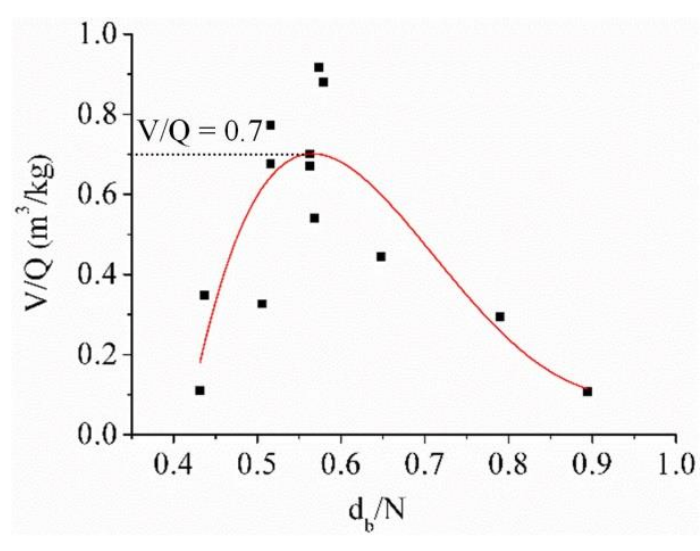

Fig. 3 Crater curve of V/Q versus $\Delta=\mathrm{d}_{\mathrm{b}} / \mathrm{N}$

\section{Preliminary design for 30-m raising blast}

To minimize the interference on production demand, an abandoned cavity under level of $1366 \mathrm{~m}$ is first taken into consideration and this cavity was scanned by using the C-ALS. Fig. 4a and 4b show its plan view and profile, respectively. As can be seen, the cavity has dimensions of roughly $32 \mathrm{~m}$ long, $22 \mathrm{~m}$ wide, and $12 \mathrm{~m}$ high, and the average vertical thickness of rock mass above the cavity is $30 \mathrm{~m}$. The surface elevation is $1367.40 \mathrm{~m}$ and the cavity mainly locates at elevations from 1325.05 to $1337.05 \mathrm{~m}$.

In practice, no matter what raising blast technique is applied, the length that the raise can be advanced in one blast depends on the hole layout, charging pattern, delay interval, expansion room, hole deviation, and inherently complicated properties of rock mass, etc. Any variation in these aspects can result in a poor advance or total failure known as "raise freezing". Therefore, all these aspects should be carefully designed and addressed to ensure a successful blast.

The design of a raise-scale VCR multiple deck blast in the cover of this abandoned cavity is to scale up the above cratering results. According to the Livingston theory, as long as the deviation from true spherical charge (diameter $=$ length) is not less than diameter-to-length of charge ratio of 1:6, the breakage mechanism and the results are practically the same as that of a true spherical charge. To be 
conservative, a diameter-to-length of charge ratio of 1:4 is adopted in this design and the same emulsion explosives as used in crater tests are used throughout the present study.

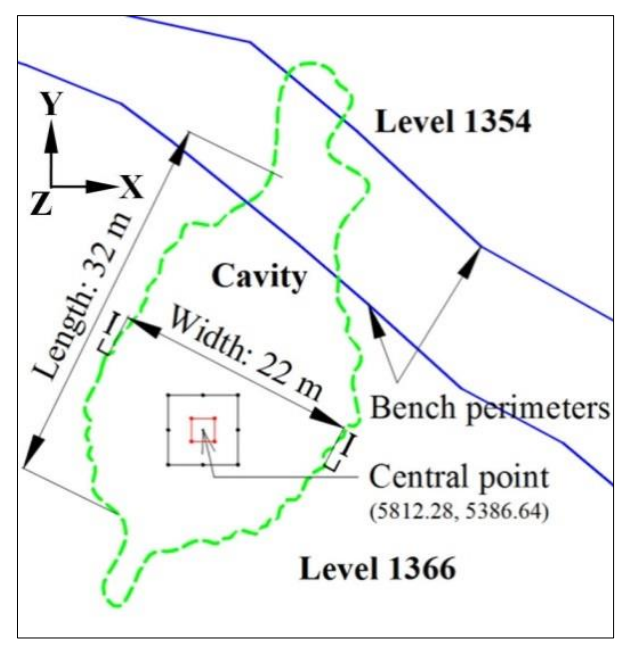

(a) Site plan view

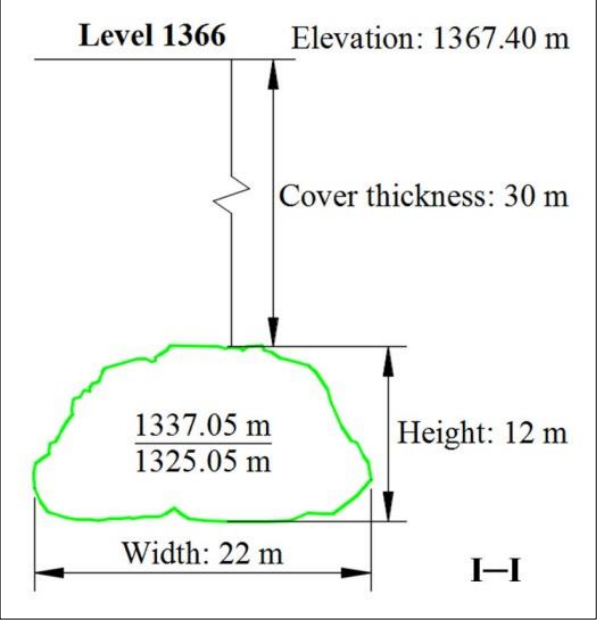

(b) Site profile

Fig. 4 Sketch of cavity location and site dimensions

Currently two types of drilling rigs with the capabilities of $140-\mathrm{mm}$ and $250-\mathrm{mm}$ hole diameters are equipped for drilling operations of relatively large diameter holes at the mine, hence different schemes based on these two available hole diameters can be designed respectively. However, for a similar size of raise cross section, more holes of $140-\mathrm{mm}$ in diameter are needed, and the number of slices will be inevitably increased compared to a scheme with 250-mm diameter holes. Moreover, at Sandaozhuang open-pit mine, 140-mm diameter holes are drilled with ITH drill rigs, in comparison to 250-mm diameter holes which are drilled using a KY-250D rotary percussive drilling machine, although longer holes also can be drilled, the accuracy is not guaranteed. The raising technique of VCR multiple deck shots in one blast, presented in this paper, is quite complex, in which the drilling and charging processes need a lot of attention. The complexity, difficulty and labour-intensity of the process increase with the increase of number of holes and slices. Any little mistake of delay system, such as wrong group, misconnection, current leakage, damage of detonator lead wire caused by sharp edges or tight kinking, etc., could be a common cause of a misfire. So for simplicity and to ensure a successful blast, in the present study, scheme with 250-mm hole diameter is recommended.

For each hole of $250-\mathrm{mm}$ in diameter, the charge weight is $54.0 \mathrm{~kg}$ with a charging density of $1100 \mathrm{~kg} / \mathrm{m}^{3}$ and the charge length is $1.00 \mathrm{~m}$ for each slice according to the diameter-to-length of charge ratio of 1:4. Then following the Livingston theory, it is assumed that $E=1.32 \mathrm{~m} / \mathrm{kg}^{1 / 3}$. According to Eq. (1), the critical depth $\mathrm{N}$ for $54-\mathrm{kg}$ charge weight is calculated to be about $5.00 \mathrm{~m}$. In a VCR-raising, the centre of gravity of the charge should be at the optimum distance $d_{o}$ from the bottom of each horizontal slice in a vertical upward direction: $d_{o}=\Delta_{0} \mathrm{~N}=0.56 \times 5.00=2.80 \mathrm{~m}$, and hence the height $\mathrm{H}$ for each horizontal slice will be: $\mathrm{H}=\mathrm{d}_{\mathrm{o}}+1 / 2 \mathrm{~L}=3.30 \mathrm{~m}$. Besides the dimensions in the vertical direction, it is important to ensure complete breakage of the rock between two adjacent holes in the raising by designing an optimum spacing between the holes. The recommended hole 
spacing $S$ should be in the range of $1.1 \mathrm{~d}_{\mathrm{o}}$ to $1.2 \mathrm{~d}_{\mathrm{o}}$, i.e., 3.08 to $3.36 \mathrm{~m}$. Considering that the $\Delta_{\mathrm{o}}$ of 0.56 is still slightly greater as mentioned above, it is more prudent to design the first raising blast using conservative slice height and hole spacing. Hence the design parameters in the vertical direction are finally determined to be: $\mathrm{Q}=54.0 \mathrm{~kg}, \mathrm{~L}=1.00 \mathrm{~m}, \mathrm{H}=3.00 \mathrm{~m}$. For the hole layout with a rectangular pattern, two different separations, inner hole spacing of $2.0 \mathrm{~m}$ and perimeter hole spacing of $3.0 \mathrm{~m}$, are adopted. The rectangular hole layout and charging pattern with $250-\mathrm{mm}$ hole diameter are shown in Fig. 5a and 5c, respectively.

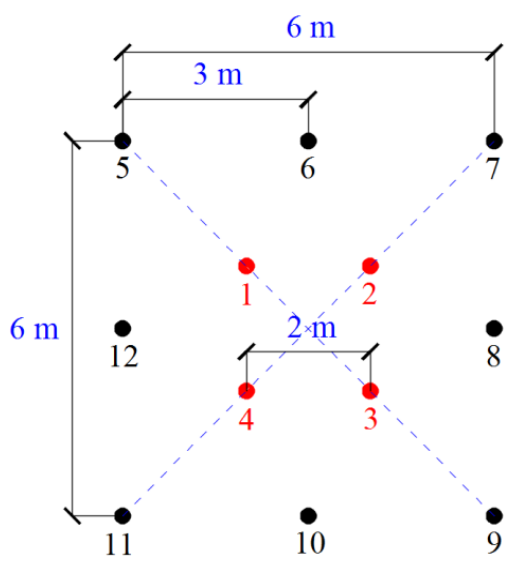

(a) Rectangular hole layout

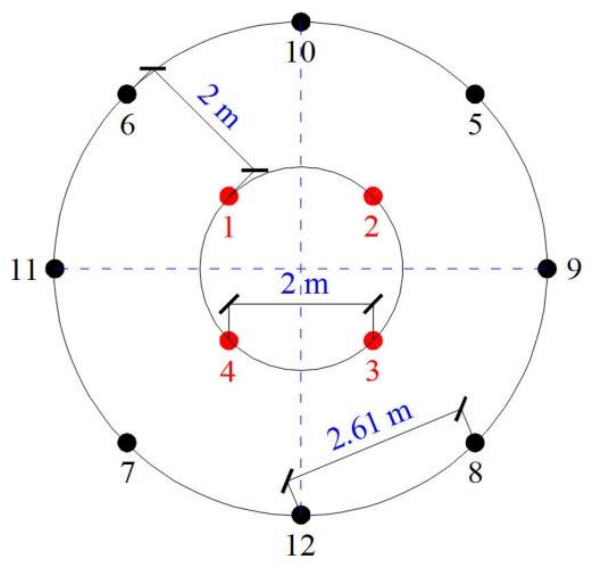

(b) Circular hole layout

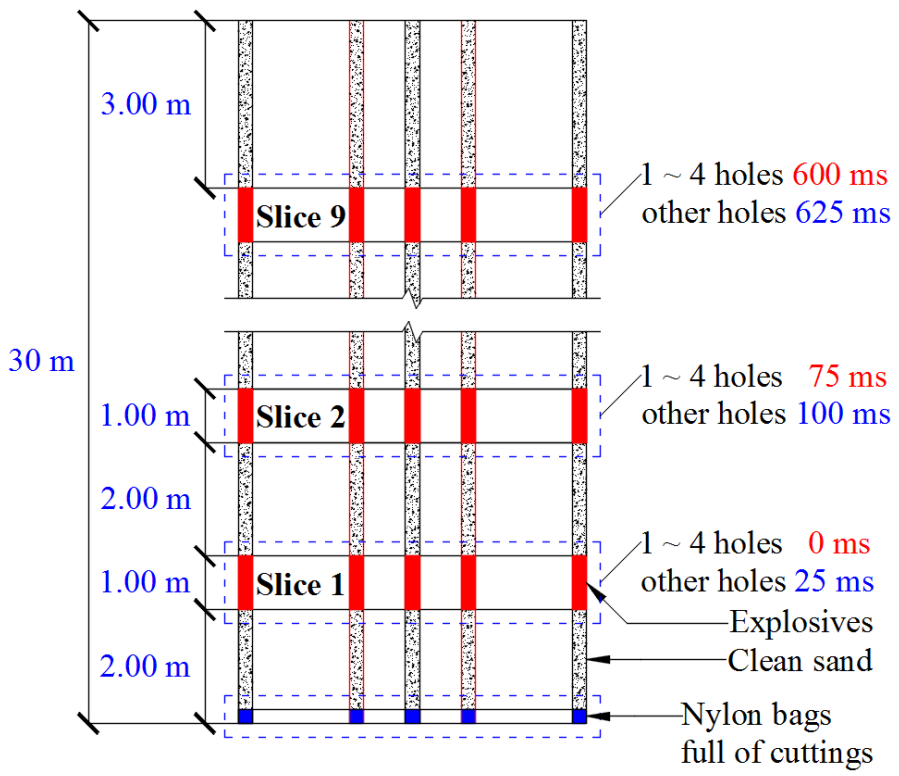

(b) Charging and timing patterns

Fig. 5 Rectangular and circular hole layouts, charging and timing patterns

Successive blasting delays should be used wherever possible to ensure that there is sufficient time for the rock from each hole, or group of holes, to be broken and ejected before firing the subsequent holes. In this design, rock will be shot in successive horizontal slices, starting from the top of the abandoned cavity and advancing upward. Through blasting, the broken rock swells to nearly $150 \%$ of its in-place volume with a swell factor of $50 \%$. According to shrinkage stoping method, at least one-third height of the blasted rock must be drawn off continuously to maintain suitable 
headroom between the back and the top of the blasted rock for the shot of next slice. Therefore, when the height of horizontal slice is $\mathrm{H}$, an expansion room of $1 / 3(1.5 \mathrm{H})$ should be provided for shot movement and expansion of each horizontal slice, i.e., the next slice can be shot only when the blasted rock moves downward at least to a $1 / 3(1.5 \mathrm{H})$ distance. Considering the gravity, one can find that:

$$
1 / 3(1.5 \mathrm{H})=\mathrm{v}_{0} \mathrm{t}_{\mathrm{m}}+1 / 2 \mathrm{gt}_{\mathrm{m}}{ }^{2}
$$

where $t_{m}$ is the minimum delay time between shots of successive horizontal slices, $v_{0}$ is the velocity of the ejected rock mass, for engineering design purpose, this velocity can be assumed in the range between 15 to $30 \mathrm{~m} / \mathrm{s}$, corresponding to the spall out velocity of rock mass under shock wave. Here $\mathrm{v}_{0}$ is preliminarily assumed to be $25 \mathrm{~m} / \mathrm{s}$, and then the calculated minimum delay time is $59 \mathrm{~ms}$. In accordance to the specifications of electric detonators, the delay interval between successive slices is determined to be $75 \mathrm{~ms}$. The designed blast timing pattern is shown in Fig. 5c.

In raising blast, providing enough expansion room is very important to avoid subsequent fires tending to "freeze" and fail. For the blasting pattern designed above, it has a cross section of $6.0 \mathrm{~m} \times$ $6.0 \mathrm{~m}$ as shown in Fig. 5a. After blasting, the broken rock will swell to $1620 \mathrm{~m}^{3}$ with a swell factor of $50 \%$. Assuming that the broken muck has an angle of repose of $45^{\circ}$, then an inversely funnel-shaped muck pile of $11.57 \mathrm{~m}$ high and $23.14 \mathrm{~m}$ diameter will be formed. Considering the additional room provided by the blasting at the bottom of the raise, the abandoned cavity under consideration, which has dimensions of $22 \mathrm{~m}$ long, $32 \mathrm{~m}$ wide and $12 \mathrm{~m}$ high, can provide adequate expansion room for the broken muck.

It should be noted here that the purpose of the above calculation is to confirm if enough expansion room is available for successive slice shots. However, the foregoing assumption on muck pile, in which it was treated as inversely funnel-shaped, is not necessarily correct. Under the influence of gravity and blasting, the fragmented rock will drop and extend laterally in all directions in the cavity, and the distributed area will be far beyond the pile formed under static condition at the bottom of the cavity. This is going to be verified by the later raising blast.

\section{Raising tests}

In the last section, aiming at an abandoned cavity with an average of 30-m cover, a scheme of multiple deck blasting based on VCR drop-raising method has been designed for excavating the backfill raise. To check the effectiveness of the above design, field blast needs to be carried out to observe the blast performance. For the purpose of testing and optimization of all factors, the 30-m high raising blast is divided into two single blasts, i.e., the lower four slices are blasted first, and the blast of the upper five slices will be redesigned based on the performance of the first blast. After these two blasts, detailed investigations will be performed and the VCR raising blast design can be modified accordingly for other raisings. 


\subsection{2-m raising using one blast}

To a great degree, the length that the raising can be advanced depends on the accuracy of drilling. Almost all literature on raising blast places drilling accuracy as the most critical factor for the success of the raise blasting. Hole deviation could cause even a perfectly designed round to fail. Without accurate drilling a number of issues can occur in the pattern. These issues include borehole intersections, increased or decreased burden, all of which can result in dead pressing or sympathetic detonation [16]. In comparison to the conventional VCR drop-raising method, the technique of VCR multiple deck raising using one blast will be a lot more sensitive to hole deviation. Thus, drilling accuracy is of utmost importance in the present study. One of the main ways of preventing deviation is to understand where it comes from and its causes. Langefors and Kihlström [17] pointed out generally the deviation comes from three places: collaring placement, initial alignment and drilling deviation inside the rock. The first two causes can be controlled by properly setting up the driller on the rock face and the third one can be controlled by the capability of drilling equipment.

To minimize drilling errors as much as possible, the holes were collared as shown in Fig. 4a with great precision by using a GPS and a value of $10 \mathrm{~cm}$ was considered as an acceptable alignment error. All holes were drilled using a KY-250D rotary percussive drilling machine, and this machine has a maximum penetration rate of about $2.1 \mathrm{~m} / \mathrm{min}$ with $250-\mathrm{mm}$ in diameter hole. The maximum drill hole deviation was controlled within $0.5 \%$ at $30 \mathrm{~m}$. Holes were drilled downward until they break through into the cavity. Prior to charging, the C-ALS was lowered into each hole, through its built-in infra-red camera, to check the borehole conditions. Visual inspection on the borehole walls showed that there was no obvious fracture and intersection between the holes.

Each of the charging steps was conducted for all the holes at one time so that the charges were at the same elevation and depth. Each hole was measured for length first, and then the hole was blocked using a tie wire attached nylon bag which was full of drill cuttings. Following the blockage, clean sand was poured into the hole until a subtotal height of the blockage of about $2 \mathrm{~m}$ was achieved. At this point, ten emulsion cartridges were slit lengthwise and dropped. Then a booster containing a 400-ms in-hole electric delay detonator was lowered into the hole. The detonator lead wire extended to ground surface with a number mark and cutoff took place when it was connected to the surface electric delay detonator. After that, another eight emulsion cartridges were dropped into the hole to raise the first slice height to $3.00 \mathrm{~m}$ and placing the charge for the first slice was completed. It should be noted here that due to the uneven cavity roof, the height of blockage and sand was slightly different from $2 \mathrm{~m}$ in each hole to keep the charges at the same level for all the holes. Furthermore, for the first slice charging, the holes were drilled penetrating the cover and the bottom was blocked. This was done because although in theory pre-setting the blockage by not drilling through is possible and the charging could be simplified, in practice, the drilling usually cannot reach the expected position over the cavity roof due to the deviation inside the rock mass. More importantly, considering the long-term exposure and no support elements in there, the roof was in poor conditions with a remarkable 
reduction in strength, rock falls may happen under the influence of drilling disturbance, thus blockage failure can be incurred. The above charging cycle was repeated for the subsequent three slices. After completion of the fourth slice, the holes were stemmed with 2-m drill cuttings on top of the explosives. By stemming, the upper section of the holes can be protected, and this is very important for conducting the left 18-m raising blast. The charging and timing patterns are shown in Fig. 6a.

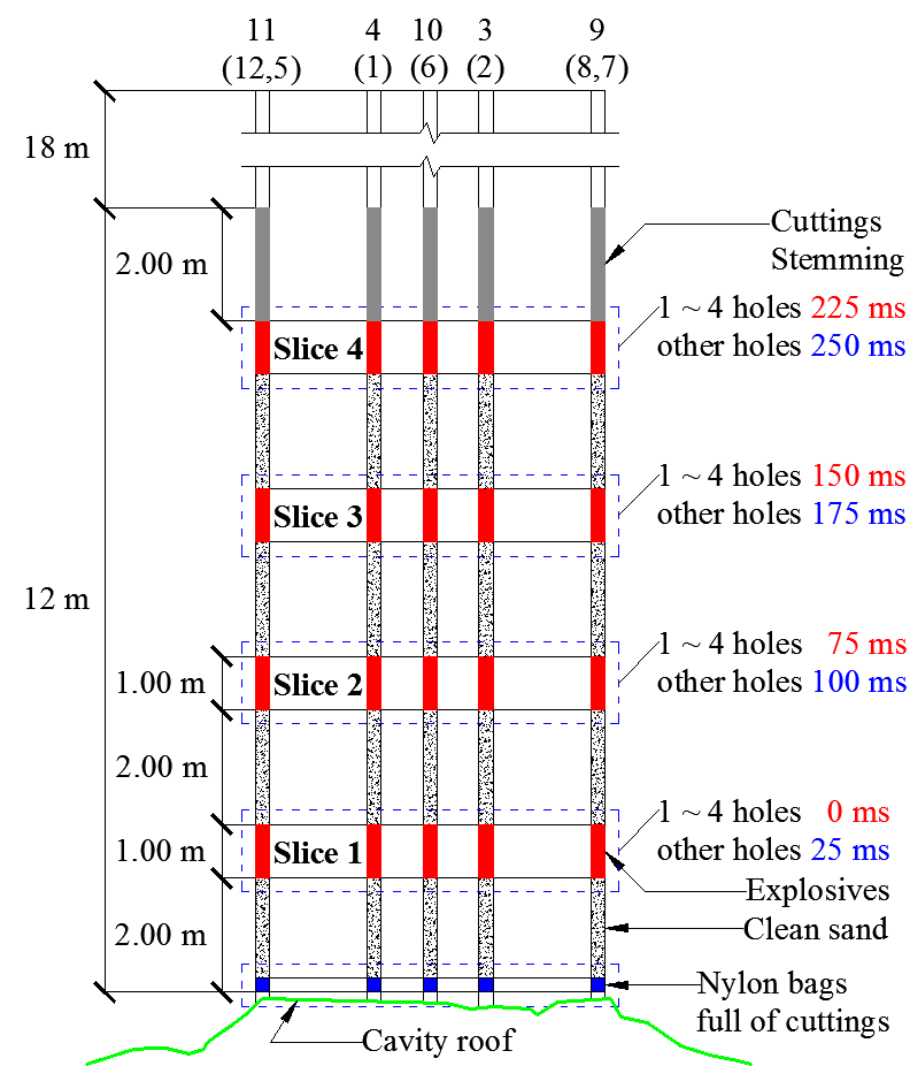

(a) Charging and timing patterns

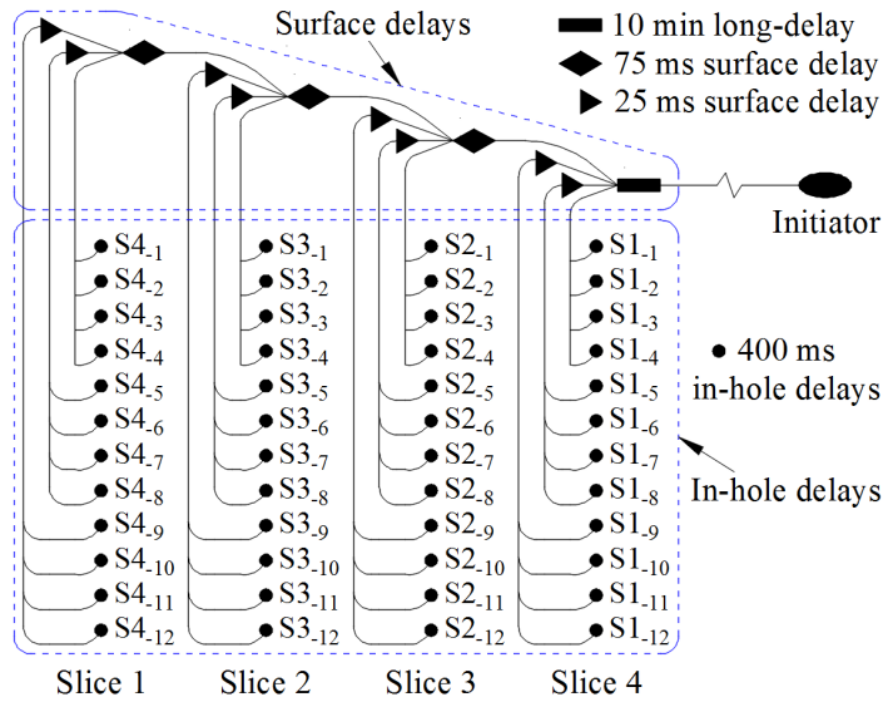

(b) Blasting circuit

Fig. 6 Charging and timing patterns and blasting circuit of 12-m raising blast

After installing charges in all the holes, detonator lead wires of each horizontal slice on ground surface were grouped and connected to different surface delays according to perimeter and inner holes. 
Fig. $6 \mathrm{~b}$ shows the blasting circuit. The setup steps of blasting circuit used are as follows: First, the detonator lead wires of perimeter holes (No. 5 12) of each slice were hooked up to two 25-ms surface electric delay detonators according to the mark numbers. Then the other ends of the two 25-ms surface electric delay detonators together with the four detonator lead wires of inner holes (No. 1 4) of this slice were hooked up to a 75-ms surface electric delay (or a 10-min long-delay electric detonator only for Slice 1). Next, the other end of the 75-ms surface electric delay detonator was further hooked up to the prior 75-ms surface electric delay detonator according to initiation sequence (or the 10-min long-delay electric detonator for Slice 2). Finally, the other end of 10-min long-delay electric detonator was hooked up to the initiator.

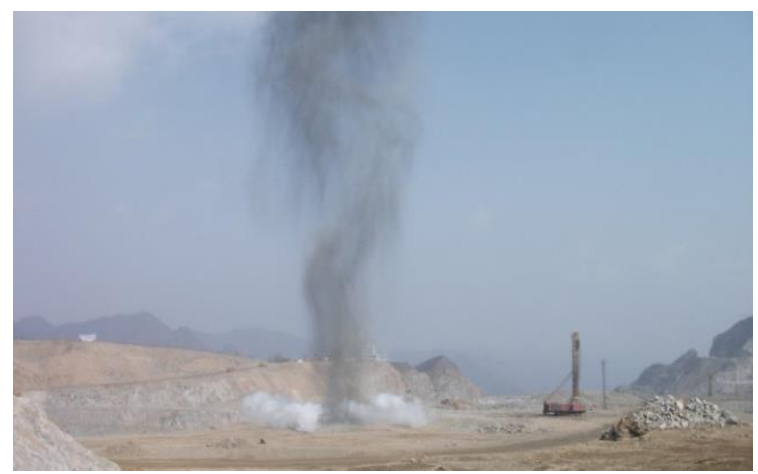

(a) Blasting scene

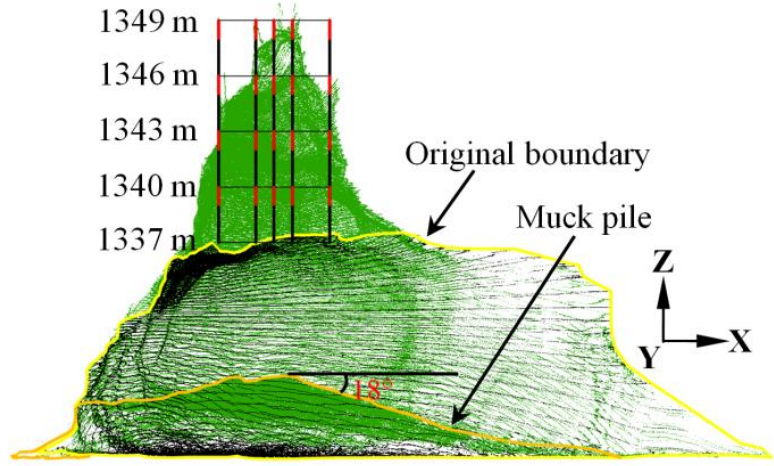

(c) Data before and after blasting

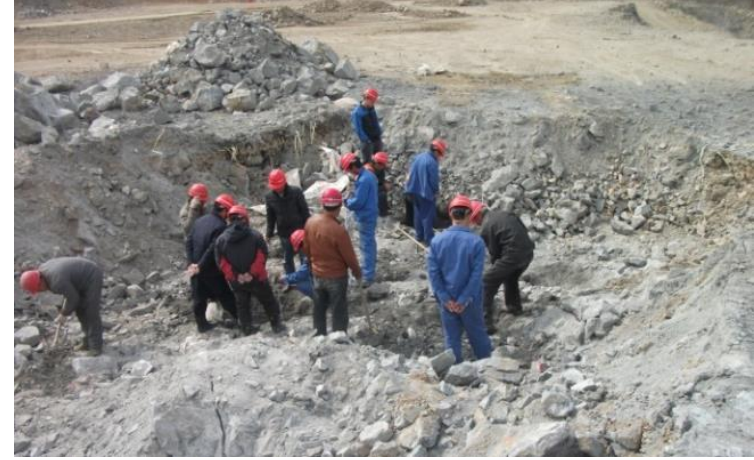

(b) Overlay digging

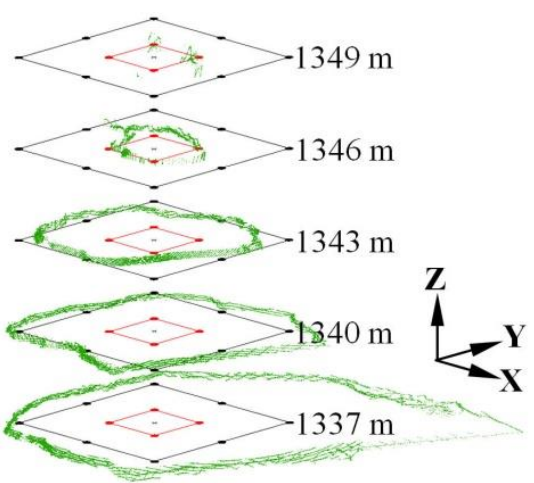

(d) Horizontal contours

Fig. 7 12-m raising blast and comparison of scanned point cloud data

Fig. 7a shows the blasting scene. During the blasting, a thin layer rock was blasted upward. After that, it was found that the rock mass directly above the blasting holes was fragmented and a round shallow pit appeared. This is obviously because of the accumulative effect of impact energy from the successive shots of lower four horizontal slices. When the compressive stress waves induced by the successive shots travelling upward were reflected at ground surface as tensile stress waves, the top rock mass was broken and hove apart. Especially when the raising was not able to penetrate through to the cavity but confined in the rock mass, the impact energy from restrained shots could not be released downward but propagated upward, which intensified the damage effect at ground surface. On the other hand, since part of the impact energy inevitably propagates upward and causes damage near 
ground surface during raising blast, this can be rationally utilized to increase stemming height when designing the top slice of the charging pattern.

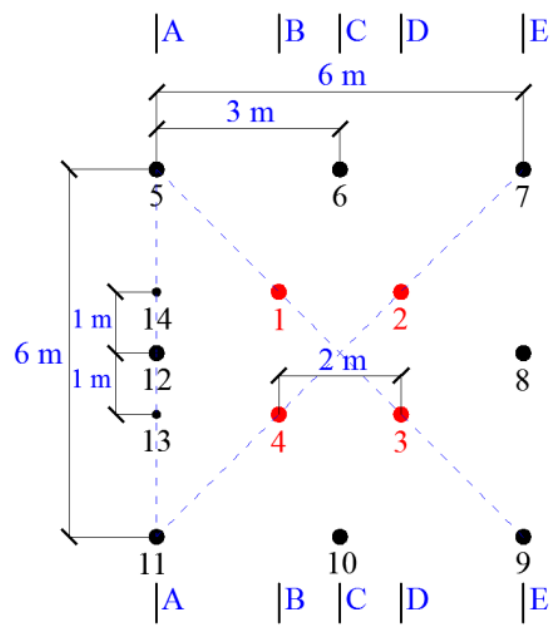

(a) Hole layout

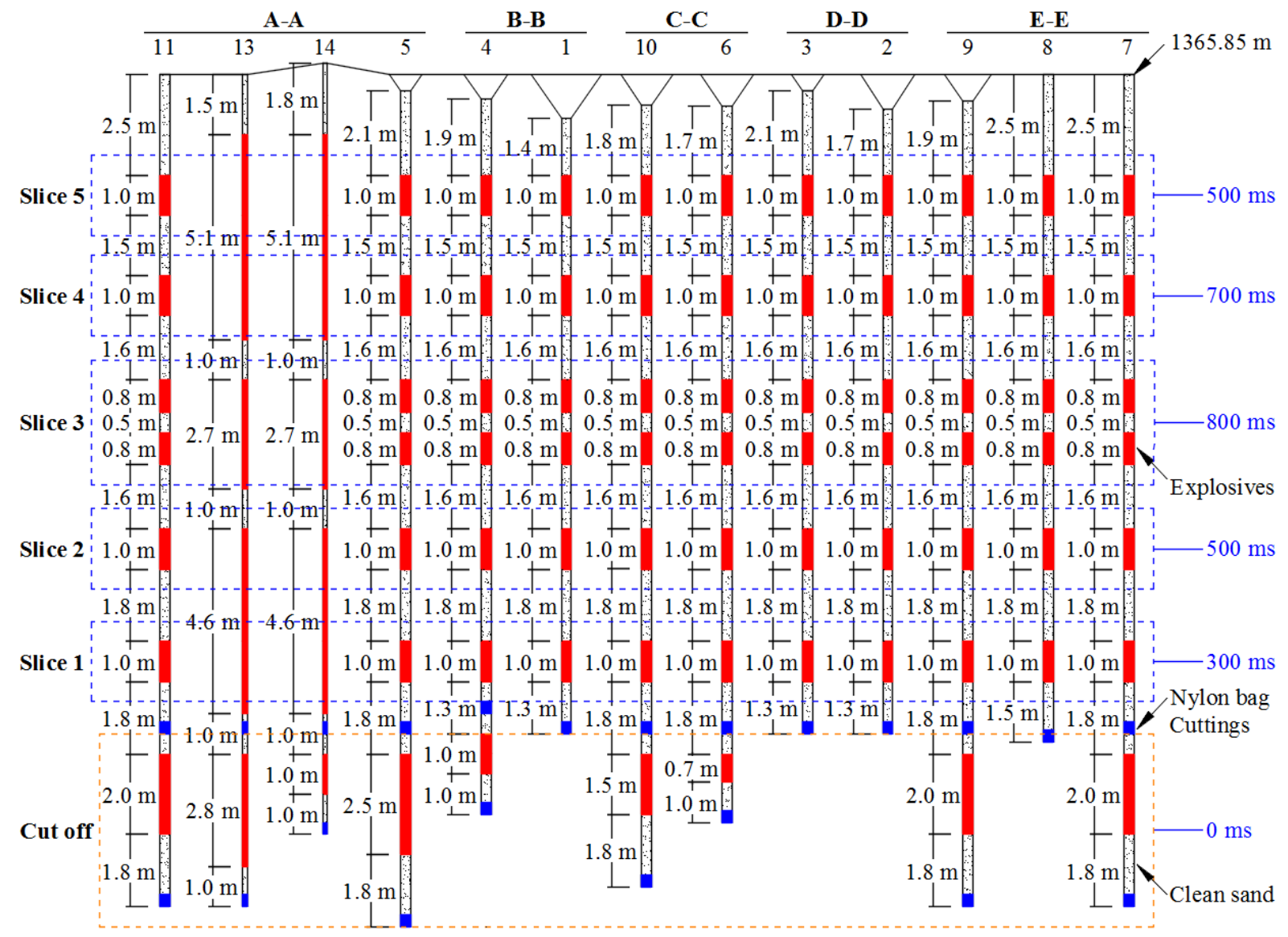

(b) Charging and timing patterns

Fig. 8 Hole layout, charging and timing patterns of $18-\mathrm{m}$ raising blast

Since the hole collars were buried, the overlay was dig out manually as shown in Fig. $7 \mathrm{~b}$ for measuring the freshly blasted raise through holes and redesigning raising blast for the left $18-\mathrm{m}$ cover. The freshly blasted raise was scanned using C-ALS through holes No. 4, 9 and 10, and the scanned point cloud data were superposed. Fig. $7 \mathrm{c}$ compares the scanned point cloud data after blasting and that of the original cavity. As can be seen, some holes can be observed from the top of the scanned 
raise data and they basically coincide with the designed positions, indicating that the drilling machine is capable of drilling holes with a very high accuracy and the drilled holes meet the design requirement. As mentioned in Section 4, the broken muck at cavity bottom extended laterally in all directions and the angle of muck pile is far less than the angle of repose of $45^{\circ}$. This indicates that, compared to static muck piling the cavity can offer more expansion room in this kind of raising blast, which is also very positive for backfilling.

Along the holes in the $Z$ direction, five typical height positions of the charging pattern $(1337 \mathrm{~m}$ to $1349 \mathrm{~m}$ ) spaced at every 3 meters (shown in Fig. 7c) are specified to derive the contours of blasted raise as shown in Fig. 7d. As can be seen, a roughly 12-m high inversed crater has been formed, which is obviously not close to the expectation of a cuboid or cylindrical raise. The five horizontal sections are much similar to the crater at different depths and ground surface in cratering theory mentioned previously. The biggest contour is obtained at $1337 \mathrm{~m}$ and as the height increasing, the upper contours gradually shrink. Especially at $1349 \mathrm{~m}$, the round almost failed except inner holes were expanded. This indicates that during the blasting the rounds gradually tended to freeze up and this blasting design is obviously infeasible. Therefore, the design of holes, charging and timing patterns need to be revised.

\section{$5.218-m$ raising using one blast}

The blast in this section is the succession of 12-m raising blast. The purpose of this blast is to break through the left 18-m cover and make the raise open into ground surface. After the foregoing 12-m raising blast, the advantage is that there are two free surfaces available, i.e., the ground surface and the back of the freshly blasted raise. However, some significant issues are unavoidable. First, because of the freeze, the section size at the bottom of the cover is limited and far smaller than the designed dimensions of $6 \times 6 \mathrm{~m}$. Second, although the ground surface provides a perfect free surface, the upper part will be blasted upward, thus it is difficult to achieve good heave due to gravity. Third, it is difficult to break the height barrier of roughly $12 \mathrm{~m}$ which was determined through last blast by adopting the previously designed scheme. Therefore, for the left 18 -m cover, the blasting scheme need to be redesigned based on the first blasting result.

The original holes except hole No. 12 are used because although the cuttings stemming was used to protect the upper section of the holes, hole No. 12 and the very bottom of holes No. 7, 8 and 9 were destroyed by the impact of last blast. So two more 140-mm diameter holes (No. 13 and 14), 1 meter away on each side of hole No. 12 along the $Y$ direction as shown in Fig. 8a, are drilled. The freeze part left by the last raising blast needs to be cut off first, by blasting the freeze part towards the pattern centre, to enlarge the free surface to dimensions of $6 \times 6 \mathrm{~m}$ at the bottom. The left cover is divided into five horizontal slices. The two lower slices are hove towards the cavity and the two upper slices are hove upward. Double-deck charges are used in the middle slice which is taken as the final breaking through round, and it will be blasted upward and downward simultaneously. In this slice, downward blasted rock is designed to be hove into the cavity, and the upward blasted rock is designed to be 
interacted with the fragmented rock from the two upper slices and finally falls into the raise bottom due to gravity. The cut off of freeze part and the five sequentially delay decked shots are combined together by a surface delay setting between them.

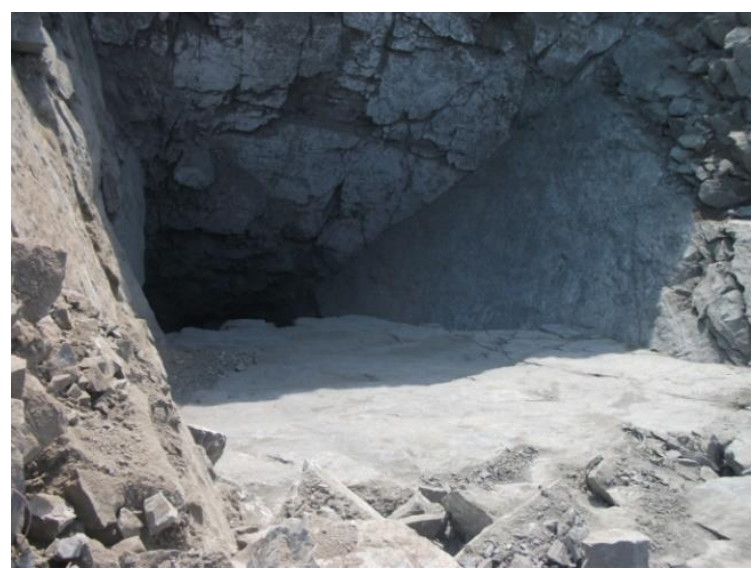

(a) Raise site

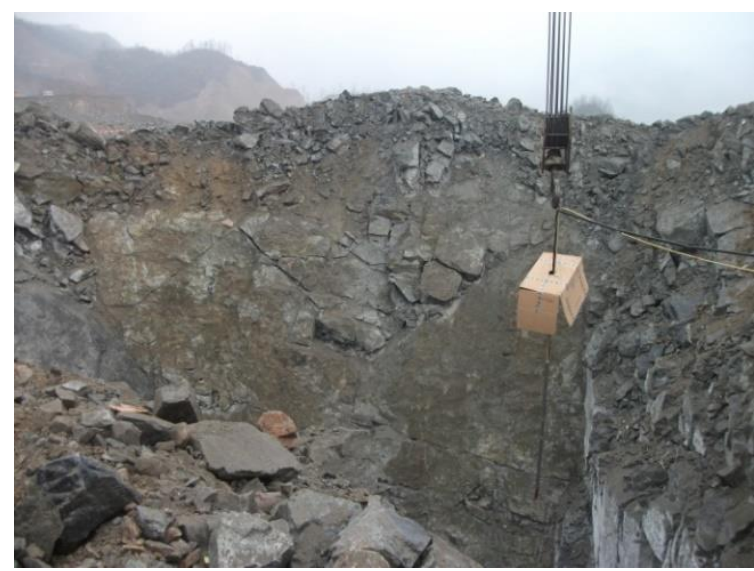

(b) Scanning

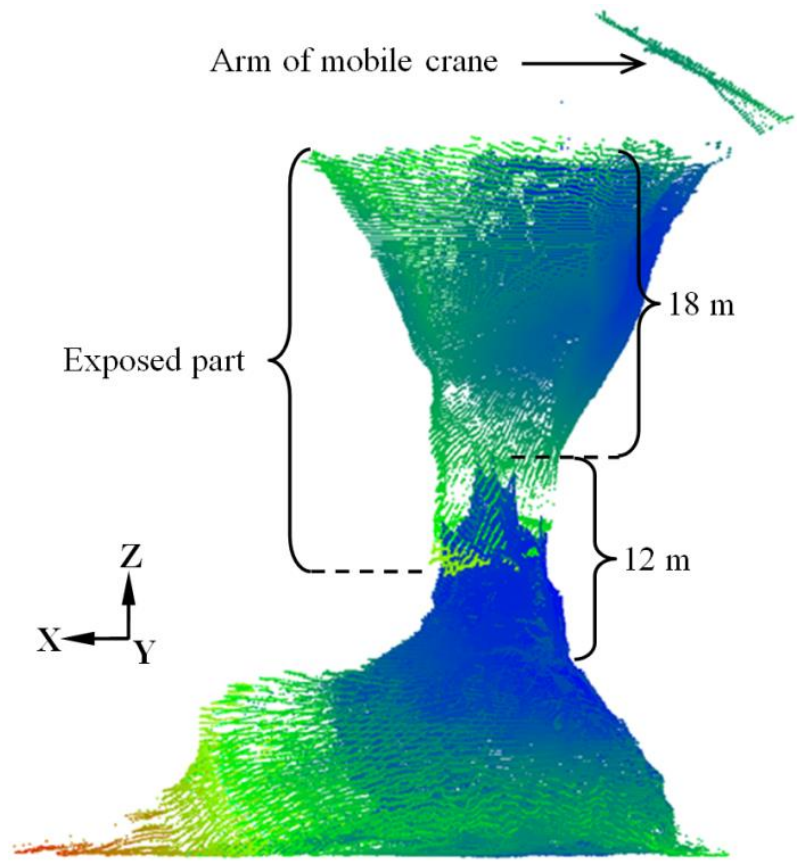

(c) Superposition of scanned data

Fig. 9 Raise site, scanning and superposition of scanned point cloud data before and after 18-m raising blast

Since the overlay was dug out to locate the holes, the collars went to different depths lower than surrounding ground. Therefore, careful consideration is given to the stemming heights to keep the charges of each slice at the same elevation and depth. The charging pattern is designed along the holes in five longitudinal sections (A-A, B-B, C-C, D-D and E-E as shown in Fig. 8a) and is shown in Fig. 8 b. As can be seen, after the first blast, it is quite complex to conduct the subsequent blasting. Holes need to be remeasured and designed respectively and carefully according to the actual residual lengths. Considering the safety of operating on the freshly blasted raise, it is obviously inadvisable to excavate the raise with more than one blast. 


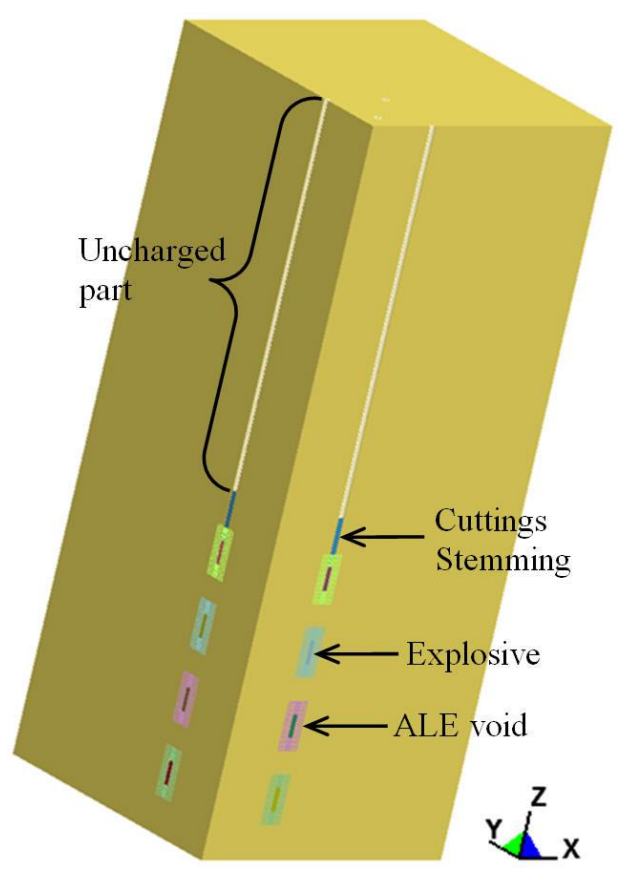

(a) Configuration of numerical model (one quarter)

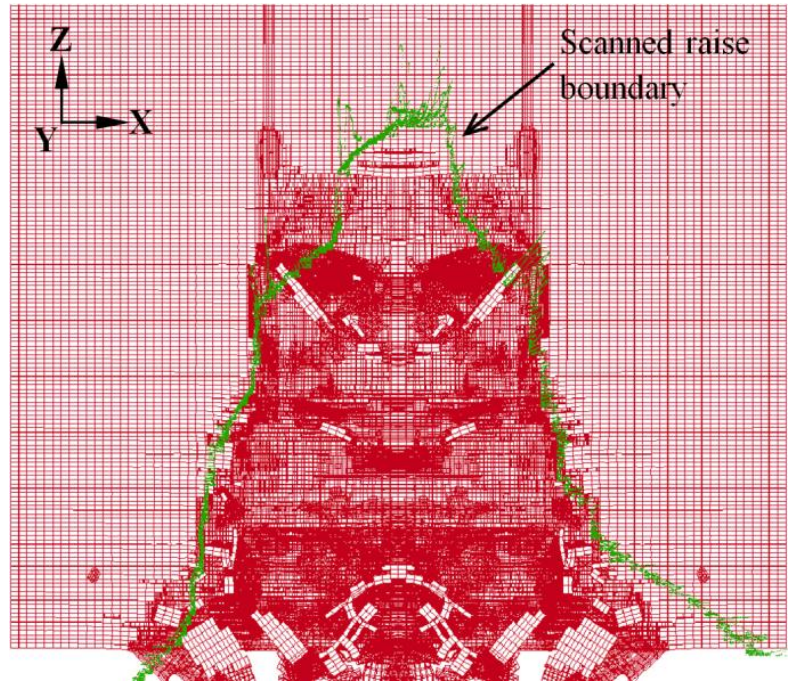

(b) Simulated raise and scanned raise boundary

Fig. 10 Model configuration and comparison of simulated raise and scanned raise boundary

Similarly, sequential delays are also set up in this blast, but no delay interval between inner and perimeter holes of each slice is adopted anymore. Furthermore, considering the delay interval of 75 ms may be not long enough, it is enlarged to $200 \mathrm{~ms}$ between the successive slice shots and $300 \mathrm{~ms}$ between the Cut off and the first slice shot. The timing is organized in sequence as: Cut off, Slice 1, Slice 2 and Slice 5, Slice 4, and Slice 3 as shown in Fig. 8b.

Fig. 9a shows the raise site after the second blast. As can be seen, a large span funnel-shaped excavation appeared on the top of the raise. To study the effect of blasting, the raise was scanned by lowering the C-ALS, which was fixed on the hook of a mobile crane, into the raise as shown in Fig. 9b. Fig. 9c shows the superposition of scanned point cloud data before and after the 18-m raising blast. As can be seen, the left 18 - $\mathrm{m}$ cover was successfully broken through and a total 30-m raise opened 
into ground surface was formed. Obvious overbreak appeared as the raise approaching to ground surface and the section size at the bottom of the $18-\mathrm{m}$ raise is basically consistent with the expectation. The height barrier of $12 \mathrm{~m}$ was broken. Compared to the first blast, the advantage of two available free surfaces was maximized. Roughly half room of the previous 12-m raise formed by the first blast was full of broken muck, i.e., the actual volume of broken muck was much greater than the calculated expansion volume. This is obvious because of the overbreak at the upper part of $18-\mathrm{m}$ raise and the overbreak is probably partly caused by the smaller slice height adopted in the charging pattern as shown in Fig. 8b, which intensified the blasting effect at upper slices. In considering the muck piling at an angle much smaller than $45^{\circ}$, it can be thought that most of the cavity has been filled by the broken muck, and the upper part of the 30-m raise can be easily backfilled using forklifts.

\section{Blast design optimization}

Through the above two blasts, it is found that by using the original blast design, the upper rounds gradually tended to freeze up in the 12-m raising blast, and although the left $18-\mathrm{m}$ cover was successfully broken through by adjusting the delay intervals, timing sequence and charging pattern, it is mainly because the additional advantage of ground surface was maximized. For a longer raise, the success rate of VCR multiple-deck blasting is still uncertain, therefore, it is necessary to conduct an optimization study on the blast design. This optimization study is carried out by using numerical modelling.

\subsection{Numerical model and calibration}

Based on the original blast design, the 12-m raising blast is simulated first. Only a quarter of the field is modelled owing to the symmetric geometry about the $y z$ and $x z$ planes as shown in Figs. 5a and $6 \mathrm{a}$. The non-reflecting boundaries are applied to minimize the stress wave reflection at these computational boundaries, and the top and bottom are specified as free faces. The large deformation zone near the charge is solved by the Arbitrary Lagrange Euler (ALE) method and the size of ALE voids around each charge is $0.9 \mathrm{~m} \times 2 \mathrm{~m}$ (diameter by height). The model size is $9 \mathrm{~m} \times 9 \mathrm{~m} \times 30 \mathrm{~m}$ with different element sizes. The smallest elements are used in the region near the holes, while larger elements are used for the other region. The element size ranges from $0.04 \mathrm{~m} \times 0.04 \mathrm{~m} \times 0.1 \mathrm{~m}$ to 0.2 $\mathrm{m} \times 0.2 \mathrm{~m} \times 0.1 \mathrm{~m}$, and there are a total of 1880280 hexahedral elements in the numerical model as shown in Fig. 10a.

The calculations are performed using LS-DYNA. There are several constitutive models widely used for simulating the blasting-induced rock response [18-22]. In the present study, the MAT_CONCRETE_DAMAGE_REL3 (*MAT_072R3) in LS-DYNA library is chosen to simulate the rock mass behaviour, this material model is a newer version of Material Type 72 and appropriate for brittle failure of rock. The tested physical and mechanical properties of rock in the site provide the material parameters used in this study. The average density of the rock is $2980 \mathrm{~kg} / \mathrm{m}^{3}$, Poisson's ratio is 0.21 , Young's modulus is $40.93 \mathrm{GPa}$, the uniaxial compressive strength is $159.85 \mathrm{MPa}$, the tensile 
strength is $7.41 \mathrm{MPa}$, the shear strength is $29.94 \mathrm{MPa}$, and the internal friction angle is $41.98^{\circ}$. In order to simulate the blast-induced fracture of rock in the numerical model, the erosion algorithm is applied, which has the capability of treating the excessive element distortion problem. The criteria of critical tensile damage $f_{\mathrm{t}}=7.41 \mathrm{MPa}$ and maximum principal strain $\varepsilon_{\max }=0.06$ are both adopted in the present modelling. Each of them defined here is implemented independently, and once any one of the criteria in an element is reached, the element will be deleted immediately from the calculation.

Material Type 8 of LS-DYNA (*MAT_HIGH_EXPLOSIVE_BUREN) is used for the emulsion explosives and the Jones-Wilkens-Lee (JWL) Equation-of-State (EOS) is used to calculate the pressure for detonation products of high explosives [23]. The JWL EOS defines the pressure as

$$
P=A\left(1-\frac{\omega}{R_{1} V}\right) e^{-R_{1} V}+B\left(1-\frac{\omega}{R_{2} V}\right) e^{-R_{2} V}+\frac{\omega E}{V}
$$

where $A, B, R_{1}, R_{2}$ and $\omega$ are the material constants, $P$ is the pressure, $V$ is the relative volume of detonation product, $E$ is the specific energy with an initial value of $E_{0}$. The material parameters for emulsion explosives used in the present study are as follows: $A=42.0 \mathrm{GPa}, B=0.44 \mathrm{GPa}, R_{1}=3.55$, $R_{2}=0.16, \omega=0.41, E_{0}=0.501 \mathrm{GPa}$. The detonation velocity and mass density of the emulsion explosives are $4200 \mathrm{~m} / \mathrm{s}$ and $1.1 \times 10^{3} \mathrm{~kg} / \mathrm{m}^{3}$, respectively.

Using the numerical model, the 12-m raising blast described above is simulated. The numerical result is compared with the scanned raise boundary as shown in Fig. 10b. The numerical result as presented in Fig. 10b is actually formed by mirroring the FEM domain along its symmetric $y z$ plane to the left side. It can be seen that the raise dimensions obtained from numerical result agree well with the scanned data. The numerical result gives slightly larger horizontal but lower longitudinal contours at the fourth slice than the scanned raise boundary. This is partly because the void expanded by the inner holes at the top of the fourth slice hides behind. Apart from this, slight difference exists at the bottom of the raise, this may be caused by the uneven cavity roof and the different subtotal height of the blockage and sand charged at the first slice. In view of the randomness of site conditions and uncertainties, it can be concluded that the developed numerical model gives reasonably accurate predictions of raising blast in the site under consideration.

\subsection{Optimization study}

\subsubsection{Hole layout}

Traditionally, numerous rectangular patterns have successfully been used for raising blast. However, through a careful observation of the simulated blasting process of $12-\mathrm{m}$ raising, it is found that when the explosives of perimeter holes of each slice are detonated simultaneously, the shots at holes No. 5, 7, 9 and 11 are suppressed by the shots at holes No. 6, 8, 10 and 12, and inversely the shots at holes No. 6, 8, 10 and 12 are pushed by the shots at holes No. 5, 7, 9 and 11. Due to the energy consumption of interaction between these shots, the blast-induced damage zone is decreased significantly which seriously disadvantaged the blast for raising. This is because the burdens of holes 
No. 6, 8, 10 and 12 are smaller than those of holes No. 5, 7, 9 and 11 to the pattern centre as shown in Fig. 5a. Therefore, for the perimeter holes detonated simultaneously, it may be a good attempt to use identical burden to make the most of every shot. Based on the above analysis, a circular pattern is proposed. In this pattern, the four inner holes are the same as the above rectangular pattern, but the eight perimeter holes, with $250 \mathrm{~mm}$ in diameter, are evenly distributed on a concentric circle, and the burden (between inner and perimeter holes) and spacing are 2 and $2.61 \mathrm{~m}$, respectively, as shown in Fig. 5b.

\subsubsection{Effects of hole layout and in-slice delay}

With the same charging pattern as the 12-m raising blast described above, the effects of hole layout and in-slice delay on raising are investigated numerically. Besides the foregoing 12-m raising simulation, three more cases are studied in the present study. In the first case, original rectangular pattern is adopted, but no delay interval between inner and perimeter holes in each slice is set up, i.e., all the explosives of each slice are detonated simultaneously. In the second case, the above proposed circular pattern is adopted with the same delay intervals as the 12-m raising blast. In the third case, the circular pattern is adopted with no delay interval between inner and perimeter holes in each slice.

Figs. $11 \mathrm{a}$ and $11 \mathrm{~b}$ show the raises simulated by using rectangular pattern with in-slice delays (i.e., the 12-m raising blast) and without in-slice delays, respectively. As can be seen, lack of in-slice delays results in more significant overbreak (this is essentially the same phenomenon as observed from the $18-\mathrm{m}$ raising blast) and the raising is more susceptible to freeze up. In addition, the ground is badly fractured. This is because when the raising tends to freeze up, more impact energy from the restrained shots could not release downward and has to propagate upward. In comparison, less deformation and damage occur near the ground surface in the simulation with in-slice delays, and this is mainly because after the detonation of inner holes, the void blasted by the inner holes provides an inversely funnel-shaped free surface in the middle of the pattern, and when the perimeter holes are initiated, the impact energy can be better released than propagates upward. It should be noted that more severe ground damage was observed from the raising site than that in the 12-m raising blast simulation. This should be again attributed to that the rock mass near ground surface had already been fractured to a greater extent due to active open-pit operations. Fig. 11c and 11d show the raises simulated by using circular pattern with and without in-slice delays, respectively. As can be seen, the situation of no in-slice delay is very similar no matter what hole layout is used. However, compared to the $12-\mathrm{m}$ raising blast simulation, the overbreak is significantly decreased by using circular pattern and in-slice delays. The spatial shape of the raise is close to cylindrical in the lower three slices and better upward extension appears, and it is therefore verified to be a good choice for raising blast. 


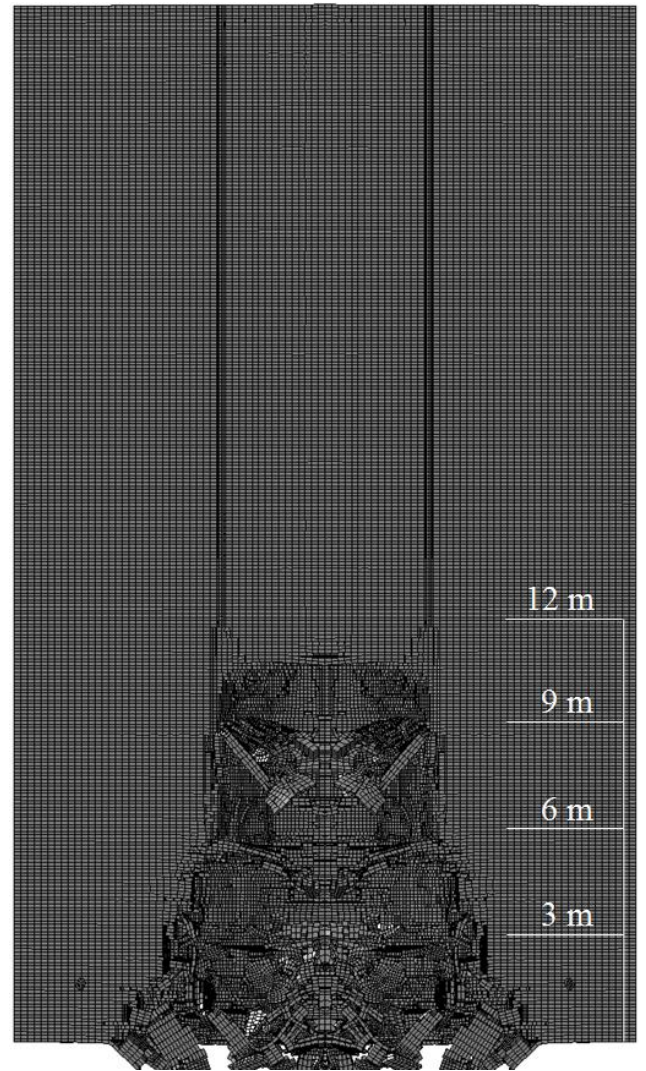

(a) Rectangular with in-slice delays

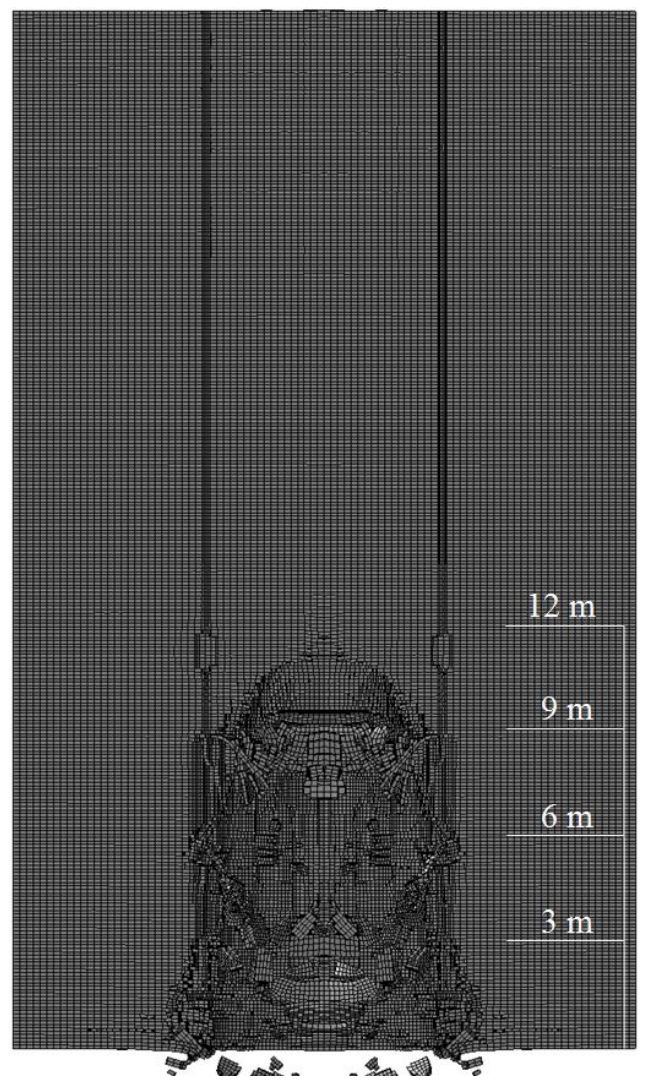

(c) Circular with in-slice delays

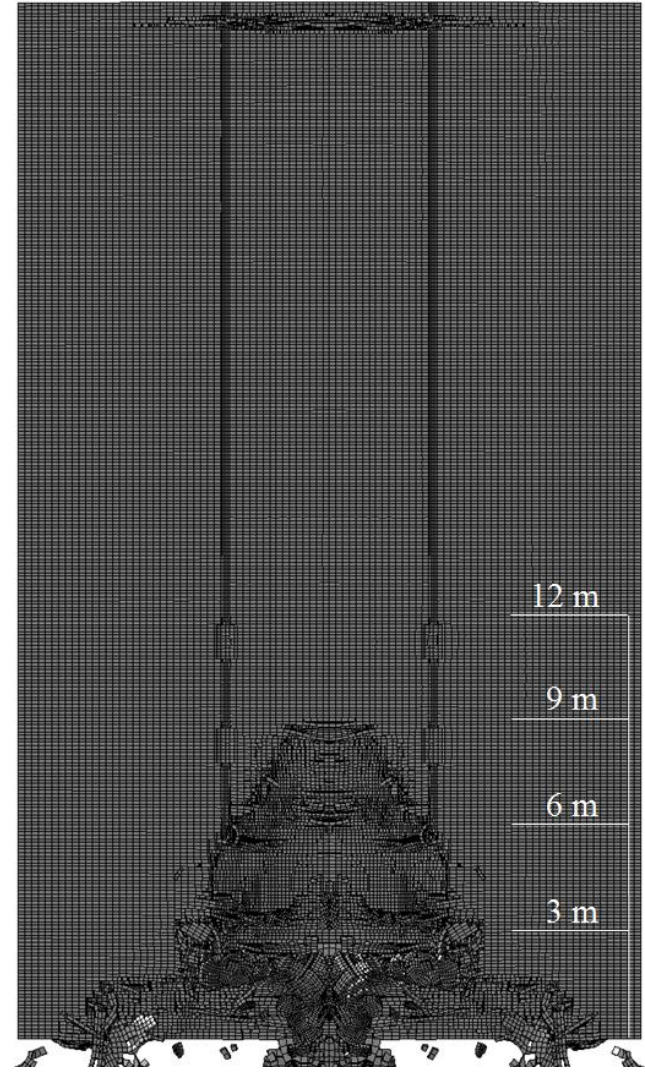

(b) Rectangular without in-slice delays

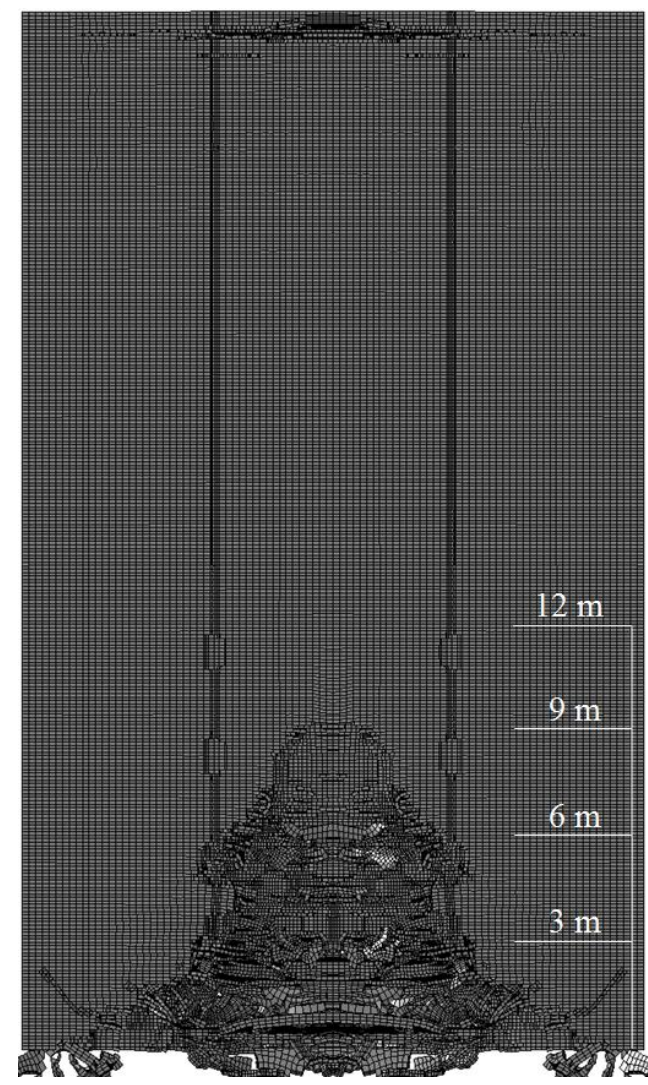

(d) Circular without in-slice delays

Fig. 11 Simulated raises for rectangular and circular patterns with and without in-slice delays 


\subsubsection{Cavity site}

To test the circular pattern with in-slice delays in practice, another abandoned cavity under level of $1354 \mathrm{~m}$ is selected to carry out a deeper raising blast. Through the C-ALS survey, it is found that the shape of this cavity is irregular, and part of its space has been filled due to a previous raising test based on long-hole drop-raising method. Figs. 12a and $12 \mathrm{~b}$ show its plan view and profile, respectively. This cavity has dimensions of roughly $36.9 \mathrm{~m}$ long, $24.2 \mathrm{~m}$ wide, and $12 \mathrm{~m}$ high, and the average thickness of the cover is about $32 \mathrm{~m}$. The surface elevation is $1352.7 \mathrm{~m}$ and the cavity mainly locates at elevations from 1308.7 to $1320.7 \mathrm{~m}$. For the proposed circular pattern, the radius of the cross section is $3.414 \mathrm{~m}$. After blasting, the 32-m high cylindrical rock mass will swell to about $1756.70 \mathrm{~m}^{3}$ with a swell factor of $50 \%$. Assuming that the broken muck has an angle of repose of $45^{\circ}$, then an inversely funnel-shaped muck pile of $11.88 \mathrm{~m}$ high and $23.76 \mathrm{~m}$ diameter will be formed. Obviously, this abandoned cavity can provide adequate expansion room for the broken muck.

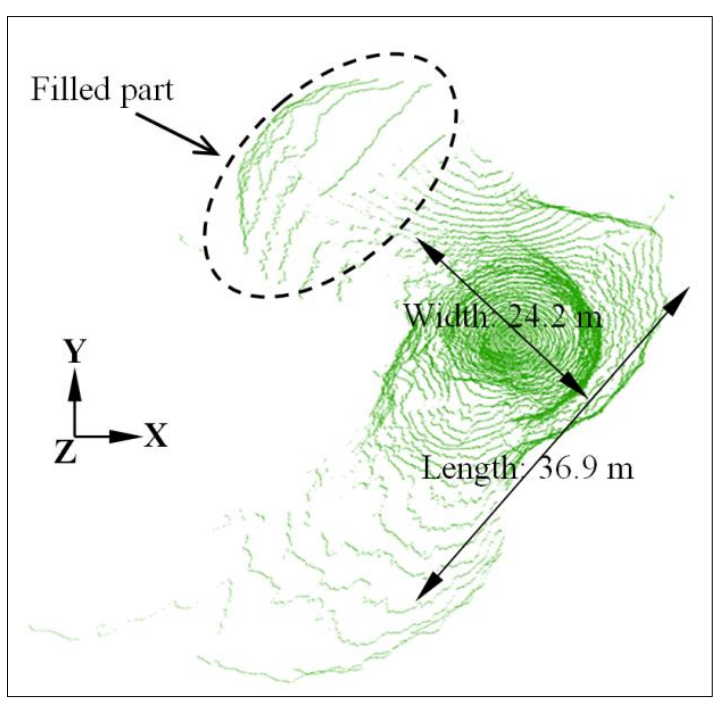

(a) Cavity plan view

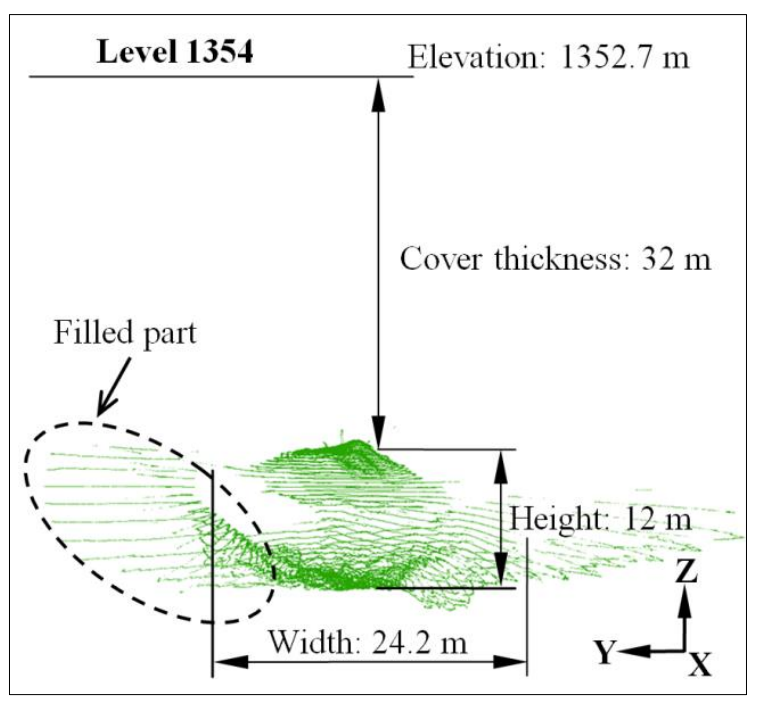

(b) Site profile

Fig. 12 Sketch of cavity location and site dimensions

\subsubsection{Charging pattern}

Based on the experience obtained from the last two raising tests, the advantage of two available free surfaces should be maximized. Therefore, like the charging of 18-m raising test, different and smaller slice heights are used in this blast design. The whole cover is divided into ten horizontal slices as shown in Fig. 13. Smaller slice height of $2.6 \mathrm{~m}$ is adopted for 1-3 slices at the bottom to provide adequate free surface for the subsequent slice shots and slice height of $2.8 \mathrm{~m}$ is adopted for 4-7 slices. Since the bedrock is covered with a thin layer of gravel, and the rock mass near ground surface is more fractured and will be successively impacted by the prior slice shots, the height of top slice, i.e., the tenth slice, is determined to be $4.0 \mathrm{~m}$, and the ninth slice is $2.8 \mathrm{~m}$. All of these slices have the same explosive height of $1.00 \mathrm{~m}$. Due to the existence of two constrained free surfaces, double-deck charges are used in the eighth slice which is taken as the final breaking through round, and it will be blasted upward and downward simultaneously to intensify the capability of breaking through. In this 
slice, clean sand was poured into the holes to create $0.6-\mathrm{m}$ high stemming separation between two 2.8-m high sub-slices whose explosive heights are both $1.00 \mathrm{~m}$.

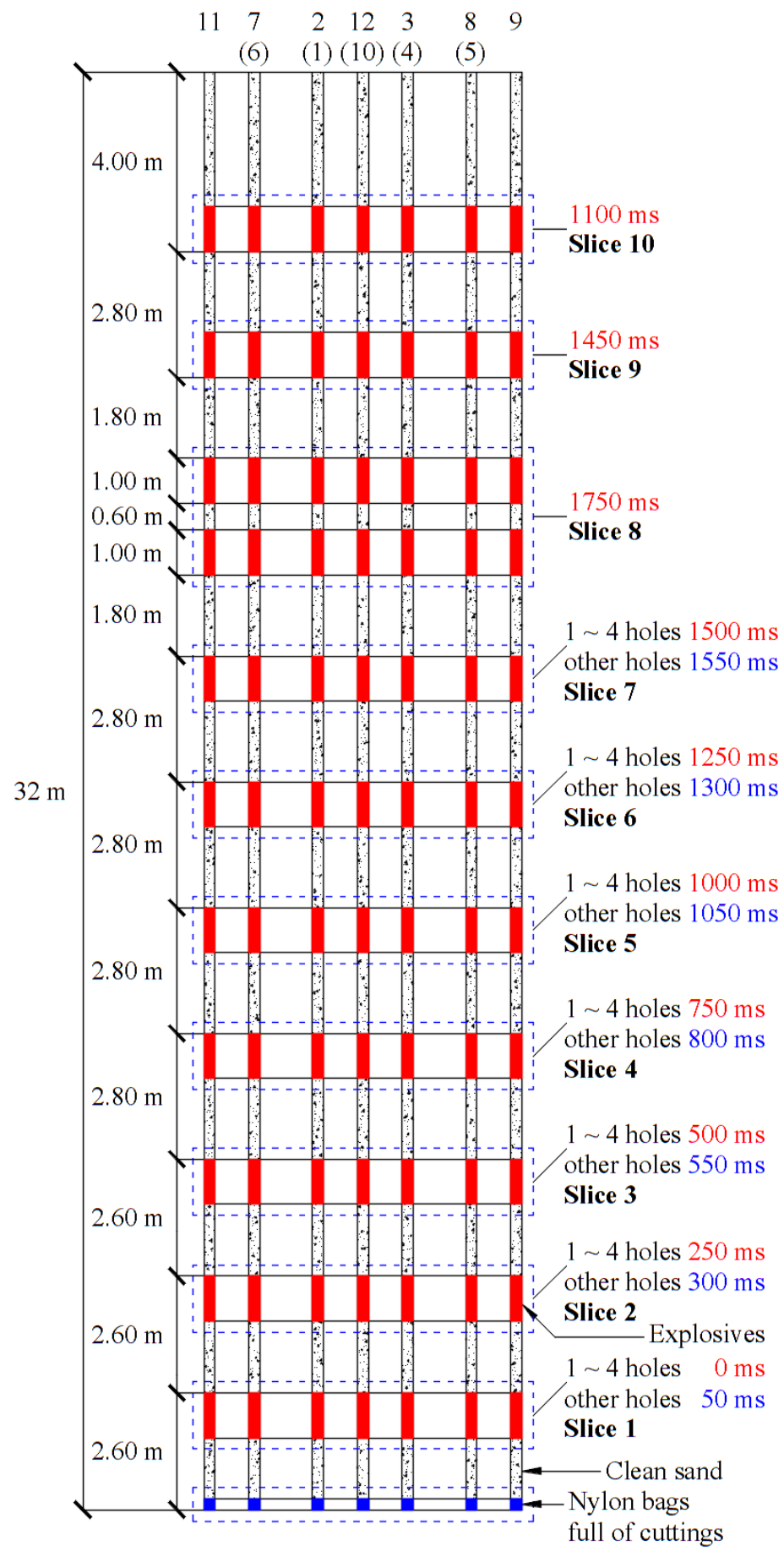

Fig. 13 Charging and timing patterns of 32-m raising blast

\subsubsection{Delay interval}

In this blast, the timing is organized in sequence as: Slice 1 to Slice 5, Slice 10, Slice 6, Slice 9, Slice 7 and Slice 8 . To completely avoid the interaction between successive horizontal slices which may result in freeze up, equation (3) is modified as:

$$
1.5 \mathrm{H}=\mathrm{v}_{0} \mathrm{t}_{\mathrm{m}}+1 / 2 \mathrm{gt}_{\mathrm{m}}^{2}
$$


which means, according to the shrinkage stoping method, only after all the blasted rock is drawn off, the next slice can be fired. According to this equation and with a conservative velocity of the ejected rock mass of $20 \mathrm{~m} / \mathrm{s}$, when the horizontal slices are blasted downward, the delay intervals are 186 and $200 \mathrm{~ms}$ for 2.6 and 2.8-m slice heights; when the slices are blasted upward, the delay intervals are 326 and $222 \mathrm{~ms}$ for 4.0 and 2.8-m slice heights. Finally, the time intervals between Slice 1 to Slice 8 are determined to be $250 \mathrm{~ms}$ and the time intervals between Slice 10, Slice 9 and Slice 8 are determined to be 350 and $300 \mathrm{~ms}$, respectively. The in-slice delays in 1-7 slices are determined to be $50 \mathrm{~ms}$. In addition, considering the upward heave and the capability of breaking through, no in-slice delays are set in Slice 10, Slice 9 and Slice 8. The timing pattern is shown in Fig. 13.

\subsubsection{Numerical simulation of $32-\mathrm{m}$ raising blast}

Using the above optimized hole layout, charging and timing patterns, numerical simulation of 32-m raising blast is conducted first. Considering that the bedrock is covered with a thin layer of gravel and the rock mass near ground surface is more fractured, only $31.5 \mathrm{~m}(2.5-\mathrm{m}$ stemming height at the tenth slice) is simulated. Fig. 14 shows the numerical raising result. As can be seen, a raise is successfully formed. The overbreak is well controlled except near the ground surface and the shape of the raise is cylindrical. Therefore, this numerical result verifies, by far, the optimized raising scheme is feasible.

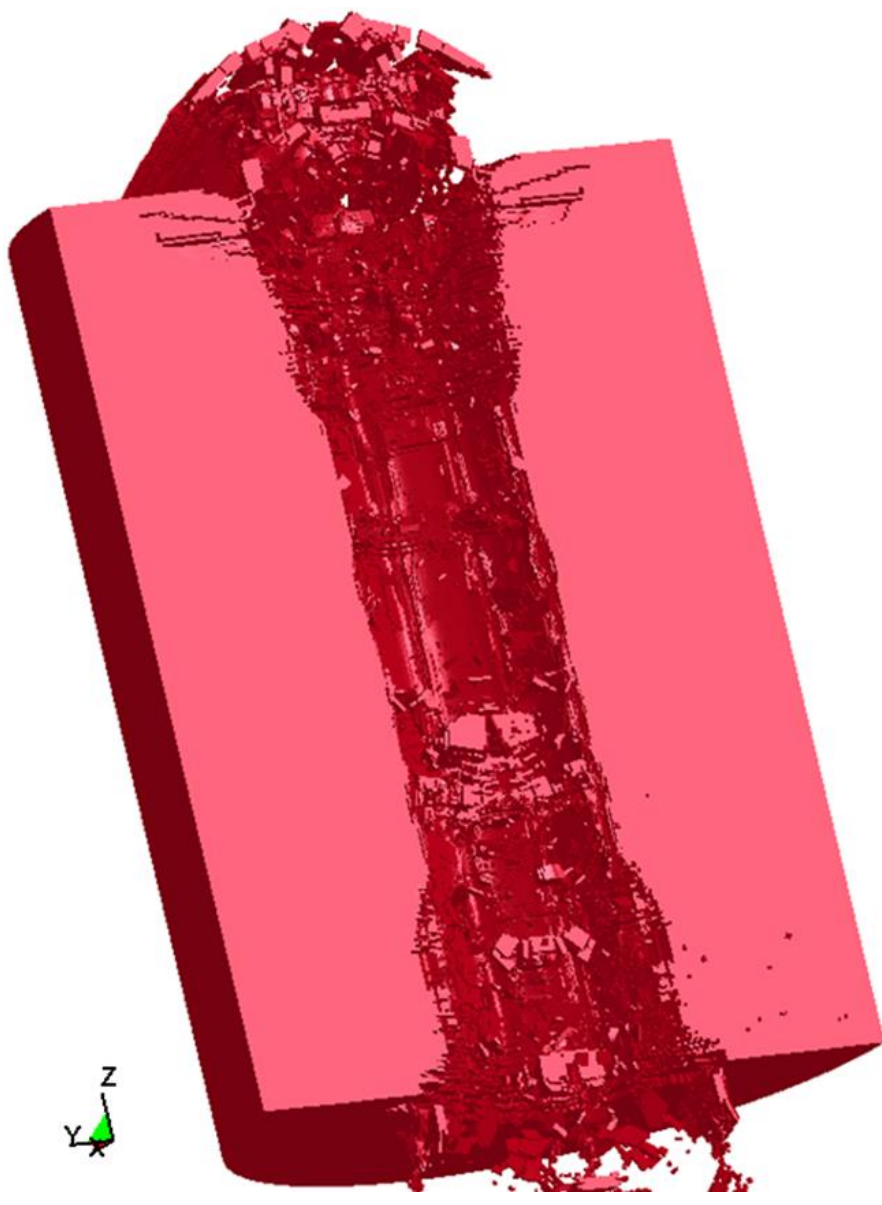

Fig. 14 Numerical result with optimized raising scheme 


\section{32-m raising using one blast}

As indicated in the numerical simulation of 12-m raising blast, when the perimeter holes of each slice were detonated simultaneously, the result deteriorated. To refine this blast, electronic detonators developed by Xian Huaqing Commercial Explosives Corp., Ltd. were used to minimize the scatter of timing. After charging all the holes, a delay was assigned to each of the detonators according to the designed delay intervals. Detonator lead wires of each horizontal slice on ground surface were grouped and clipped into a main lead wire. The main lead wire was run to the firing position and hooked up to the blast box.

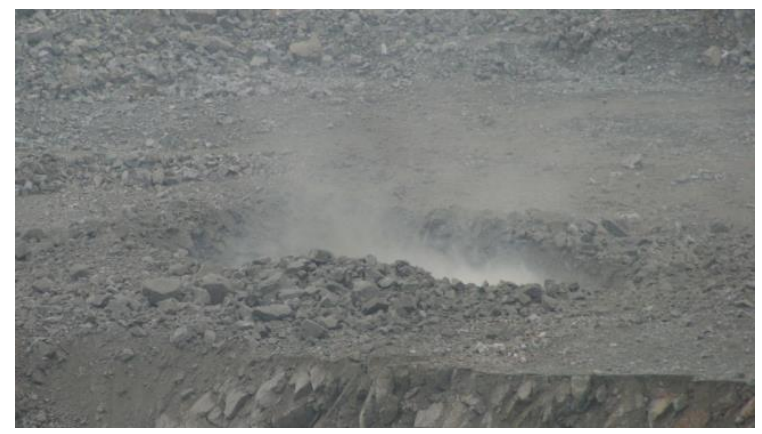

(a) Blasting scene

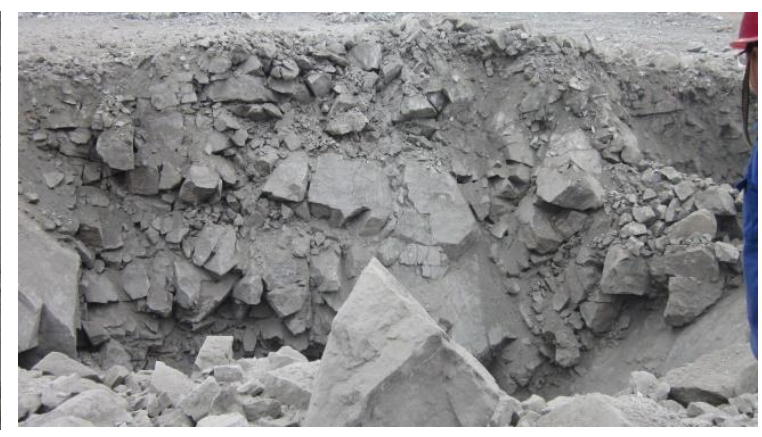

(b) Raise site

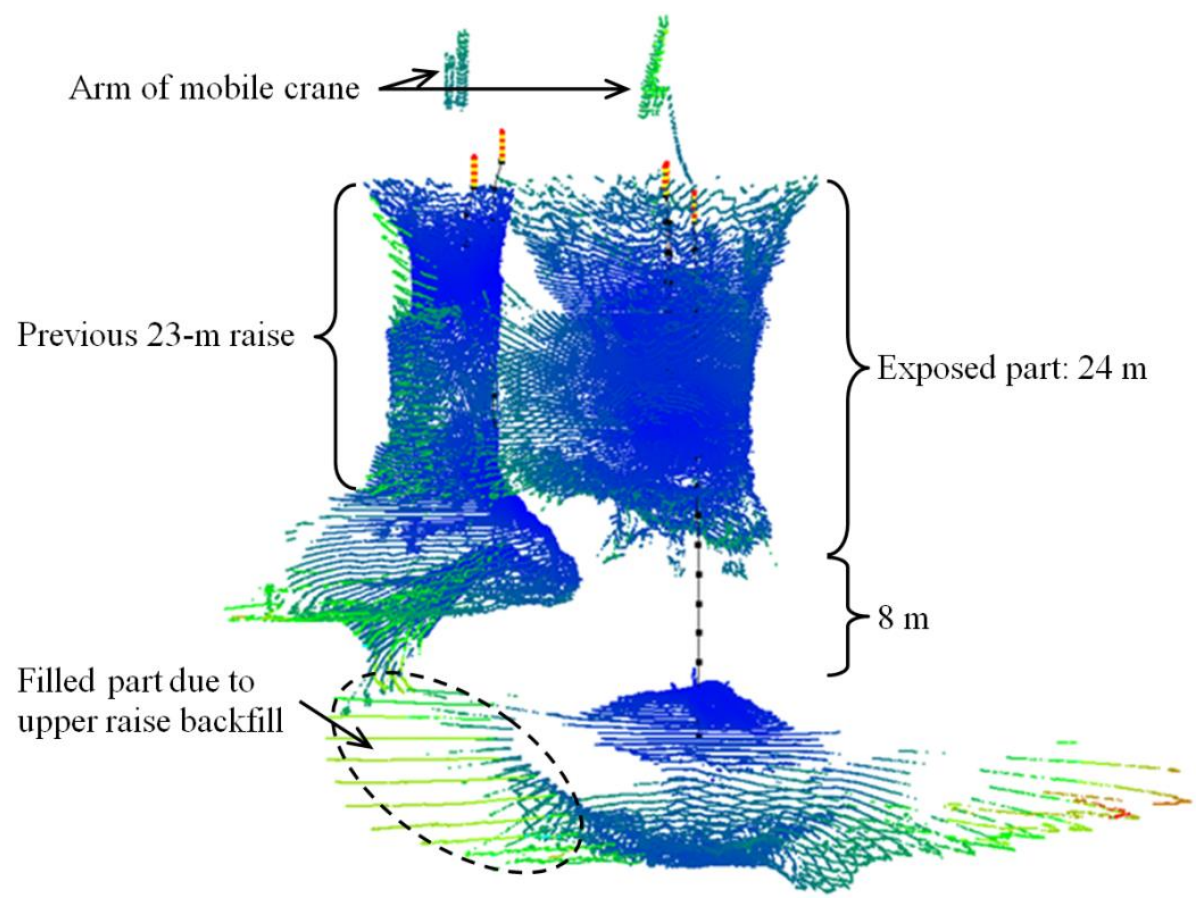

(c) Superposition of scanned data

Fig. 15 Blasting scene, raise site after raising blast and superposition of scanned data of previous unfilled raise, freshly blasted raise and the cavity

Fig. $15 \mathrm{a}$ and $15 \mathrm{~b}$ show the blasting scene and the raise site after $32-\mathrm{m}$ raising blast, respectively. As mentioned above, this blast is adjacent to a backfilled raise due to a previous raising test. From the figures, it can be told that the backfilled waste rock in the adjacent raise went to a lower depth. A 
preliminary analysis can be made that the underpart between the freshly blasted raise and the previous raise was broken through.

Scanning of the raise was performed using C-ALS. Fig. 15c shows the superposition of scanned point cloud data of the previous raise when it was not backfilled, the freshly blasted raise and its corresponding cavity before 32-m raising blast. As can be seen, same as the preliminary analysis from the scenes, the underpart between the freshly blasted raise and the previous raise has been broken through, and the backfilled waste rock flowed into the freshly blasted raise. The bottom of the freshly blasted raise was filled by broken muck and waste rock. The volume of waste rock and broken muck is roughly calculated using equation:

$$
\mathrm{V}=\mathrm{V}_{1}+\mathrm{V}_{2}
$$

where $V_{1}$ is the volume of waste rock from the backfilled raise, $V_{2}$ is the volume of the blasted rock from the freshly blasted raise and the broken through part between two raises. Through calculation, it is confirmed that $\mathrm{V}$ is roughly equal to the filled room, and therefore the overall raising blast result is excellent.

\section{Discussion}

The issue of treatment of inaccessible abandoned cavities is typical at old mines in China, especially for those open pits converted from long-term underground operations. In recent years, a number of tests with different methods, such as large-diameter borehole/pipeline, conventional drill-and-blast operations for raise excavation, etc., were carried out to backfill the cavities at Sandaozhuang open-pit mine. Initially the backfill and implementation results were not sustainable while backfilling cavity needs to be done throughout the mine's life.

With the idea of long-hole raising using one blast, two raising techniques i.e., long-hole drop-raising and VCR multiple deck shots, have been developed there. Both of them are cheaper than conventional drill-and-blast operations and introduction of additional raising equipment like raise borer, and they are safer since drilling and charging on bench surface are allowed and access from the bottom is not required. The technique of long-hole drop-raising was first attempted. In this kind of raisings, 250-mm large-diameter holes were used to provide relief volume, and smaller 140-mm holes were taken as blast holes. Although the theory was good, the results were always erratic due to the smaller burdens (minimum burden of $0.45 \mathrm{~m}$ for the first shot) between relief and blast holes for providing expansion for the remaining holes. The requirement of drilling accuracy was very strict in long-hole drop-raising operations and off-target deviations were often encountered, especially for deeper holes, which could result in the failure even before conducting a field blast. Thus the primary disadvantage of a long-hole drop-raising is its length and the scope of application is limited. The 23-m raise shown in Fig. 15b was the greatest depth achieved using one blast at the mine site based on the long-hole drop-raising method. 
Compared to the long-hole drop-raising, the raising depth can be greatly advanced by using the technique of VCR multiple deck shots because the drilled holes of 250-mm diameter can easily meet the designed hole-deviation specification. Recent practices show that this method is very forgiving to moderate levels of hole-deviation. Since only less number of large diameter holes is required, it is also very cost effective. However, this technique still has some significant shortcomings. As the VCR multiple deck shots progressing, different and smaller slice heights have to be adopted to overcome the gradually intensified freezing. To determine the height for each slice and achieve a successful blast, design and numerical calculation need to be repeated in each step and it is a very time-consuming process. The setup of in-slice delays adds to its high-complexity of implementation. Furthermore, like other VCR based methods, crater charges can cause serious surrounding rock damage, hence compromised stability of surrounding rock mass and rough raise walls can be easily incurred especially on either end of the completed raise in spite of the large amounts of overbreak at both of the ends contributing to the final opening up by providing adequate free surfaces. Thus, the simplicity of height-determination process for each slice and overbreak control have been the subjects of considerable interest in the further study.

\section{Conclusions}

Based on Livingston's cratering theory, a series of small-scale crater tests were carried out at Sandaozhuang open-pit mine. Field blasting test data were measured and the basic data for raise-scale blasting designs were obtained through data analysis and evaluation. The raising design parameters with 250-mm hole diameter, including charge weight and charge height for each slice, slice height, hole spacing with a rectangular pattern and delay interval, were derived. A scheme of multiple deck blasting based on VCR drop-raising method was designed for an abandoned cavity with 30-m cover and the lower 12-m cover was first blasted for investigating the blast performance in practice. The charging and timing patterns were adjusted for the upper 18 meters based on the result analysis of the first blast and the left cover was successfully opened up. Through these two single raising blasts, it is shown that the advantage of two available free surfaces up and down should be maximized for breaking the barrier of raising height in one blast, and smaller slice height and alternate initiation sequence are benefit for the raising extension of VCR multiple deck shots. A numerical model has been developed to simulate the VCR multiple-deck blasting process and it was calibrated against the 12-m raising test. By combining the calibrated numerical model with the two raising tests, a circular pattern was proposed and the effects of hole layout and in-slice delay were examined numerically. It is shown that circular pattern and in-slice delay are positive for the VCR multiple-deck raising blast. Aiming at an abandoned cavity with 32-m cover, an optimized scheme was proposed and the feasibility was verified numerically. The optimized scheme was applied to field raising blast and the cover was successfully broken through. It demonstrates that by using this long-hole raising technique of VCR multiple deck shots, the raising length in one blast can be greatly increased. 


\section{Acknowledgments}

The successful blasts of the 12-m, 18-m and 32-m long-hole raising at Sandaozhuang molybdenum mine were the result of a team effort of researchers from Central South University and personnel from Sandaozhuang Mining Company. In particular, the authors wish to thank the following people for their contributions in the work: Weihua Wang, Xiling Liu, Jinyue Li, Jingqing Zhao and Bingchuan Liu of Central South University; Shigun Jing, Shangde Mai and Jiujing Xie of Sandaozhuang Mining Company.

The authors acknowledge the financial support from the National Key Research and Development Program of China under grant number 2016YFC0600706 and Natural Science Foundation of Hunan Province, China under grant number 2018JJ3656 for carrying out this research work.

\section{Reference}

1. Liu KW, Hao H, Li XB. Numerical analysis of the stability of abandoned cavities in bench blasting. Int J Rock Mech Min Sci. 2017; 92: 30-39.

2. Liu KW, Li XB, Gong FQ, Liu XL, Wang WH. Stability analysis of complicated cavity based on CALS and coupled Surpac-FLAC3D technology. Chinese Journal of Rock Mechanics and Engineering. 2008; 27(9): 1924-1931 [in Chinese].

3. Landriault DA. Backfill in underground mining. In: William AH, Richard LB. editors. Underground Mining Methods. Colorado: Society for Mining, Metallurgy, and Exploration, Inc. (SME); 2001. p. 601-614.

4. Emad MZ, Vennes I, Mitri H, Kelly C. Backfill Practices for Sublevel Stoping System. Mine Planning and Equipment Selection. 2014: 391-402.

5. Ferreira PH. Mechanised mine development utilising rock cutting and boring through raise and blind boring techniques. The Third Southern African Conference on Base Metals. Kitwe, Zambia: The South African Institute of Mining of Mining and Metallurgy. 2005: 297-314.

6. Shaterpour-Mamaghani A, Bilgin N. Some contributions on the estimation of performance and operational parameters of raise borers - A case study in Kure Copper Mine, Turkey. Tunnelling and Underground Space Technology. 2016; 54: 37-48.

7. Sachse U, Westgate N. Rockpasses: a guide to excavation methodology. The Journal of The South African Institute of Mining and Metallurgy 2005; 105: 759-764.

8. Lang LC. Vertical crater retreat: An important mining method. In: Richard EG, Richard LB, editors. Techniques in Underground Mining. USA: Society for Mining, Metallurgy, and Exploration, Inc.; 1998. p. 329-342

9. Ferreira PH. Improved technologies in longhole blast hole drilling, applied to dropraising and longhole stoping as well as the application of a small twin boom mechanized drillrig. The Journal of The South African Institute of Mining and Metallurgy 2003. p. 233-240. 
10. REVEY Associates, Inc.Tunnels, shaft and development headings blast design. Underground Blasting Technology. 2005: 1-48.

11. Sterk PV. Development of drop raise blasting at the Homestake mine. Proceeding of the 17th Annual Conference on Explosives and Blasting Technique. Las Vegas, NV (United States); 1991; V1: 239-250.

12. Fellows, GL, Stolp G. The integration of a cavity monitoring system and computer triangulations for longhole stope analysis at Echo Bay's Lamefoot Mine. Paper presented at the annual meeting of the Northwest Mining Assocaiation, Spokane, WA; 1997.

13. Innovation news: Inverse box hole blasting at Elandsrand. International Mining; 2010. p. 43-44.

14. Liu Q, Tran H. Techniques of inverse drop raise blasting and slot drilling. Cim Bulletin 2000; 93(1039): 45-50.

15. Livingston, C.W., 1973, U.S. Patent 3,762,771, Oct. 2.

16. Allen RM. An analysis of burn cut pull optimization through varying relief hole depths. Master Thesis, Missouri University of Science and Technology, Missouri, US, 2014, p. 9.

17. Langefors U, Kihlström B. The Modern Technique of Rock Blasting, John Wiley \&Sons, Inc., New York, USA, 1963. p. 230-257.

18. Ma GW, An XM. Numerical simulation of blasting-induced rock fractures. Inter J Rock Mech Min Sci 2008; 45(6): 966-75.

19. Wei XY, Zhao ZY, Gu J. Numerical simulations of rock mass damage induced by underground explosion. Int J Rock Mech Min Sci 2009; 46(7): 1206-13.

20. Hao H, Wu CQ, Zhou YX. Numerical analysis of blast-induced stress waves in a rock mass with anisotropic contimuum damage models. Part 1: Equivalent material property approach. Rock Mechanics and Rock Engineering; 2002; 35(2): 79-94.

21. Hao H, Hao YF, Li J, Chen WS. Review of the current practices in blast-resistant analysis and design of concrete structures. Advances in Structural Engineering. 2016; 19(8): 1193-1223.

22. Wang ZL, Li YC, Shen RF. Numerical simulation of tensile damage and blast crater in brittle rock due to underground explosion. Int J Rock Mech Min Sci 2007; 44: 730-738.

23. Livermore Software Technology Corporation (LSTC). LS-DYNA keyword user's manual, Version R 8.0. Livermore CA, 2015. 